\title{
PROPERTIES OF FOAM CONCRETE PREPARED FROM MAGNESIUM OXYCHLORIDE CEMENT
}

\author{
JIAQI ZHOU*, PANPAN LIU*, ${ }^{*}$ CHENGYOU WU*, **, ZEJIN DU*, JINGPING ZONG*, \\ MENG MIAO*, RUIYANG PANG*, HONGFA YU*** \\ *School of Civil Engineering, Qinghai University, Xining 810016, PR China \\ ** Qinghai Provincial Key Laboratory of Energy-saving Building Materials and Engineering Safety, Xining 810016, PR China \\ **Department of Civil Engineering, Nanjing University of Aeronautics and Astronautics, Nanjing 210016, PR China
}

"E-mail: wuchengyou86@163.com

Submitted September 23, 2019; accepted December 9, 2019

\begin{abstract}
Keywords: Foam concrete, Molar ratio, Admixture, Microstructure, Structural characteristics
To broaden the application of magnesium oxychloride cement (MOC) in thermal insulation materials, lightly burned magnesia powder and magnesium chloride hexahydrate were used as the main raw materials of cement and a chemical foaming method was used to prepare a magnesium oxychloride cement foam concrete (MOCFC) with fast hardness and early strength. By changing the molar ratio (M) of the MOCFC and adding different dosages of hydrogen peroxide $\left(\mathrm{H}_{2} \mathrm{O}_{2}\right)$, fly ash (FA), potassium dihydrogen phosphate (KDP) and other admixtures, while measuring and observing the compressive strength and flexural strength at 3, 7, and 28 days, the thermal conductivity, dry apparent density, volume water absorption, softening coefficient, and other parameters, combined with its hydration phase composition and microscopic appearance, the effect of the molar ratio and the admixtures on the properties of MOCFC were studied. The results show that with an increase in the molar ratio and the dosage of $\mathrm{H}_{2} \mathrm{O}_{2}, \mathrm{FA}$ and $\mathrm{KDP}$, the internal pore structure of the slurry changes significantly, which affects its mechanical properties, water resistance, and thermal insulation performance.
\end{abstract}

\section{INTRODUCTION}

Foamed concrete is also known as foamed cement, lightweight concrete. Air, nitrogen, carbon dioxide or oxygen is introduced into cement-based materials such as mortar and cement paste by physical or chemical foaming. After forming and curing, the foamed concrete contains a large number of closed pores and has a certain strength. Therefore, foamed concrete has the characteristics of having a low density, being lightweight, having heat preservation, providing sound insulation, and being earthquake resistance, it is widely used in the production of lightweight insulation panels, composite wall panels, etc.

MOC is a new type of material, which is an important inorganic gelling system composed of $\mathrm{MgO}$ $-\mathrm{MgCl}_{2}-\mathrm{H}_{2} \mathrm{O}$ [1-2]. Compared with silicate cementitious materials, it has a series of advantages such as having excellent mechanical properties, being fast setting, being refractory and lightweight [3-4], foamed concrete made of MOC has better mechanical properties and thermal insulation properties than silicate foam material. However, MOC has some major disadvantages, such as having poor water resistance, large strength loss or even disintegrating after water absorption, which restrict its engineering applications [5].

According to the influence of the water-binder ratio $(w / b)$ on the performance of the foamed concrete, studies have shown that the $\mathrm{w} / \mathrm{b}$ is an important factor affecting the performance of the foamed concrete [6-10].
For example, Jiang et al studied the effect of the w/b on the pore structure of high porosity foam concrete, and found that when the $w / b<0.8$, the pores are small, the shape is irregular, and the connectivity is strong; when the $w / b>0.8$, at the time, the pores are round and swell, with an enlarged range of the pore size distribution [11]. Yang and Lee studied the effect of the w/b on the performance of foam concrete. As the $w / b$ increases, the number of fine pores decreases, and the number of large pores increases, which results in the high porosity of the foamed concrete, resulting in a low strength [12-13]. According to the research, foam concrete has excellent thermal insulation performance. The typical thermal conductivity is between 0.23 and $0.42 \mathrm{~W} \cdot \mathrm{m}^{-1} \cdot \mathrm{K}^{-1}$ at a dry apparent density of 1000 to $1200 \mathrm{~kg} \cdot \mathrm{m}^{-3}$, but the thermal conductivity still does not meet the demand [14]. Therefore, many scholars have used $\mathrm{H}_{2} \mathrm{O}_{2}$ as a foaming agent to study the chemical foaming method to prepare the foamed concrete and to measure its thermal properties and other properties. For example, Dai et al [15] found, in their study, that with an increase in the dosage of $\mathrm{H}_{2} \mathrm{O}_{2}$, when more micro-bubbles are produced by the high-speed foam production, more micro-closed bubbles are produced in cement slurry also, so the volume of the foamed concrete increases and its dry apparent density decreases. At the same time, with an increase in the $\mathrm{H}_{2} \mathrm{O}_{2}$ dosage, the amount of closed bubbles formed in cement slurry is large, thus the net pressure surface per unit area within the compression surface is small, the compressive strength is reduced, and the water absorption rate is 
increased, so the dosage of $\mathrm{H}_{2} \mathrm{O}_{2}$ should be limited. Of course, manganese dioxide is indispensable as a catalyst for hydrogen peroxide. The manganese dioxide content directly affects the foaming rate of $\mathrm{H}_{2} \mathrm{O}_{2}$, which, in turn, affects the porosity. FA is used as an additive in foamed concrete. On one hand, FA can be used as a substitute for cement to reduce the production costs, on the other hand, FA can reduce slurry porosity, increase compactness, enhance the consistency of the mixture, and improve the long-term strength of the foamed concrete [16-19]. For example, E.P. Kearsley studied the effects of using graded FA and ungraded FA to replace a large amount of cement (up to $75 \%$ by weight) on the properties of foamed concrete [20]. The results show that the use of a large amount of FA reduces the strength growth rate of the foamed concrete, but it can replace up to $67 \%$ of the cement in the case where the long-term strength is not significantly reduced. EP Kearsley studied the effects of the porosity on the strength properties of foam concrete by adding different types and different amounts of FA. It was found that the strength of the foam concrete is related to its porosity and age, but did not show any correlation with the amount and type of FA [21]. KDP is added to foamed concrete as a modifier and reacts with $\mathrm{Mg}^{2+}$ in the MOC slurry, forming a dense and insoluble complex protective film on the surface of the hydration products, effectively preventing the hydrolysis of the $5 \cdot 1 \cdot 8$ phase and improving the water resistance of the MOCFC [22].

In this study, MOCFC is prepared by a chemical foaming method with the $\mathrm{w} / \mathrm{b}$ fixed at 0.34 . By changing the molar ratio, admixture type and dosage, we were able to measure the MOCFC mechanical properties, thermal conductivity, volume water absorption, softening coefficient and other parameters combined with its hydration phase composition and microscopic appearance, to analyse and research the results, to study the effect of them on the properties of the MOCFC.

\section{EXPERIMENTAL}

\section{Raw materials}

The magnesium oxide used in this study is light-burned magnesia (LBM) obtained by calcining magnesite from Liaoning, China at $750-850{ }^{\circ} \mathrm{C}$, and the chemical composition of the LBM is as shown in Table 1. The activity of $\mathrm{MgO}$ is determined by using the standardised hydration method of Dong Jinmei which is $59.04 \%$ [23]. The density of the LBM is $3.58 \mathrm{~g} \cdot \mathrm{cm}^{-3}$.

Table 1. The chemical composition of the lightly-burned magnesia powder.

\begin{tabular}{lcccccc}
\hline Component & $\mathrm{MgO}$ & $\mathrm{CaO}$ & $\mathrm{SiO}_{2}$ & $\mathrm{Al}_{2} \mathrm{O}_{3}$ & $\mathrm{Fe}_{2} \mathrm{O}_{3}$ & $\mathrm{CO}_{2}$ \\
\hline $\begin{array}{l}\text { Mass fraction } \\
\text { (wt. \%) }\end{array}$ & 80.20 & 1.30 & 6.07 & 0.15 & 0.41 & 11.87 \\
\hline
\end{tabular}

The magnesium chloride $\left(\mathrm{MgCl}_{2} \cdot 6 \mathrm{H}_{2} \mathrm{O}\right.$ crystal $)$ used in this study is analytically pure which was produced in Qinhai Xingda Chemical Co, Ltd. The content of the $\mathrm{MgCl}_{2} \cdot 6 \mathrm{H}_{2} \mathrm{O}$ crystal accounts for $98 \%$ of the total mass. Configure a mass fraction of the $28.9 \% \mathrm{MgCl}_{2}$ solution.

The $\mathrm{H}_{2} \mathrm{O}_{2}$ used in this study is as a foaming agent, the concentration of the foaming agent is $27.5 \%$ industrial grade $\mathrm{H}_{2} \mathrm{O}_{2}$.

The FA used in this study is from a power plant in Inner Mongolia, its chemical composition is shown in Table 2, the density of the FA is $2.15 \mathrm{~g} \cdot \mathrm{cm}^{-3}$.

Table 2. The chemical composition of the fly ash.

\begin{tabular}{lcccccc}
\hline Component & $\mathrm{Al}_{2} \mathrm{O}_{3}$ & $\mathrm{SiO}_{2}$ & $\mathrm{Fe}_{2} \mathrm{O}_{3}$ & $\mathrm{CaO}$ & $\mathrm{MgO}$ & LOI \\
\hline $\begin{array}{l}\text { Mass fraction } \\
\text { (wt. \%) }\end{array}$ & 40.88 & 42.7 & 3.66 & 2.96 & 0.36 & 5.46 \\
\hline
\end{tabular}

The KDP used in this study is analytically pure which was produced in the Tianjin Damao Chemical Reagent Factory.

The $\mathrm{MnO}_{2}$ used in this study is used as a catalyst, it is analytically pure which was produced in Tianjin Kemi Europe Chemical Co, Ltd.

The EHAA is a sodium dodecylbenzene sulfonate, which is produced in Shandong Shuangshuang Chemical Co. Ltd.

\section{Preparation of the MOCFC}

The MOCFC preparation process by chemical foaming is as follows:

- Firstly, the molar ratio $\left(\alpha-\mathrm{MgO} / \mathrm{MgCl}_{2}\right)$ of the MOCFC was determined, and the $\mathrm{MgO}$, catalyst, foam stabiliser, admixture, and powder were mixed in using an NJ-160B cement paste mixer produced by Tianjin Beichen Construction Engineering Test Instrument Factory for 1 minute at a speed of $180 \mathrm{r} \cdot \mathrm{min}^{-1}$.

- Then the $\mathrm{MgCl}_{2} \cdot 6 \mathrm{H}_{2} \mathrm{O}$ solution was added and stirred for 2 minutes to ensure that the powder and solution were evenly mixed.

- The EHAA was added and stirred for 1 minute.

- Finally, $\mathrm{H}_{2} \mathrm{O}_{2}$ was added and stirred for $30 \mathrm{~s}$ to make a uniform liquid slurry.

The slurry was poured into moulds of $100 \times 100 \times$ $\times 100 \mathrm{~mm}$ (type X), $40 \times 40 \times 160 \mathrm{~mm}$ (type Y), and $300 \times 300 \times 40 \mathrm{~mm}$ (type $\mathrm{Z}$ ), removed after curing for 24 hours under standard conditions, cured at room temperature, and then tested after curing at different ages (3, 7 and 28 days). Eighteen pieces of type $X$, six samples of type $\mathrm{Y}$, and two test pieces of type $\mathrm{Z}$ were formed, and the MOCFC preparation process is shown in Figure 1 . The raw material ratio of the test pieces is shown in Table 3 
Zhou J., Liu P., Wu Ch., Du Z., Zong J., Miao M., Pang R., Yu H.

Table 3. The raw material ratio of the test pieces.

\begin{tabular}{|c|c|c|c|c|c|c|c|}
\hline \multirow{2}{*}{ Group } & \multirow{2}{*}{$\begin{array}{l}\text { Sample } \\
\text { number }\end{array}$} & \multirow{2}{*}{$\alpha-\mathrm{MgO} / \mathrm{MgCl}_{2}$} & \multicolumn{5}{|c|}{ Quality ratio (\%) } \\
\hline & & & $\left(\mathrm{H}_{2} \mathrm{O}_{2} / \mathrm{MgO}\right)$ & $(\mathrm{KDP} / \mathrm{MgO})$ & $(\mathrm{FA} / \mathrm{MgO})$ & $\left(\mathrm{MnO}_{2} / \mathrm{MgO}\right)$ & (EHAA/MgO) \\
\hline \multirow{4}{*}{ M } & M5 & 5.0 & 7.0 & & & 0.02 & 1.0 \\
\hline & M6 & 6.0 & 6.6 & & & 0.02 & 1.0 \\
\hline & M7 & 7.0 & 6.4 & & & 0.02 & 1.0 \\
\hline & M8 & 8.0 & 6.8 & & & 0.02 & 1.0 \\
\hline \multirow{9}{*}{$\mathrm{H}_{2} \mathrm{O}_{2}$} & $0.5 \% \mathrm{H}_{2} \mathrm{O}_{2}$ & 6.0 & 0.5 & & & 0.02 & 1.0 \\
\hline & $1 \% \mathrm{H}_{2} \mathrm{O}_{2}$ & 6.0 & 1.0 & & & 0.02 & 1.0 \\
\hline & $2 \% \mathrm{H}_{2} \mathrm{O}_{2}$ & 6.0 & 2.0 & & & 0.02 & 1.0 \\
\hline & $3 \% \mathrm{H}_{2} \mathrm{O}_{2}$ & 6.0 & 3.0 & & & 0.02 & 1.0 \\
\hline & $4 \% \mathrm{H}_{2} \mathrm{O}_{2}$ & 6.0 & 4.0 & & & 0.02 & 1.0 \\
\hline & $5 \% \mathrm{H}_{2} \mathrm{O}_{2}$ & 6.0 & 5.0 & & & 0.02 & 1.0 \\
\hline & $6 \% \mathrm{H}_{2} \mathrm{O}_{2}$ & 6.0 & 6.0 & & & 0.02 & 1.0 \\
\hline & $7 \% \mathrm{H}_{2} \mathrm{O}_{2}$ & 6.0 & 7.0 & & & 0.02 & 1.0 \\
\hline & $8 \% \mathrm{H}_{2} \mathrm{O}_{2}$ & 6.0 & 8.0 & & & 0.02 & 1.0 \\
\hline \multirow{5}{*}{ FA } & $0 \% \mathrm{FA}$ & 6.0 & 5.0 & & 0.0 & 0.02 & 1.0 \\
\hline & $5 \% \mathrm{FA}$ & 6.0 & 5.0 & & 5.0 & 0.02 & 1.0 \\
\hline & $10 \% \mathrm{FA}$ & 6.0 & 5.0 & & 10.0 & 0.02 & 1.0 \\
\hline & $15 \% \mathrm{FA}$ & 6.0 & 5.0 & & 15.0 & 0.02 & 1.0 \\
\hline & $20 \% \mathrm{FA}$ & 6.0 & 5.0 & & 20.0 & 0.02 & 1.0 \\
\hline \multirow{4}{*}{ KDP } & $0 \% \mathrm{KDP}$ & 6.0 & 5.0 & 0.0 & & 0.02 & 1.0 \\
\hline & $0.5 \% \mathrm{KDP}$ & 6.0 & 5.0 & 0.5 & & 0.02 & 1.0 \\
\hline & $1 \% \mathrm{KDP}$ & 6.0 & 5.0 & 1.0 & & 0.02 & 1.0 \\
\hline & $1.5 \% \mathrm{KDP}$ & 6.0 & 5.0 & 1.5 & & 0.02 & 1.0 \\
\hline
\end{tabular}

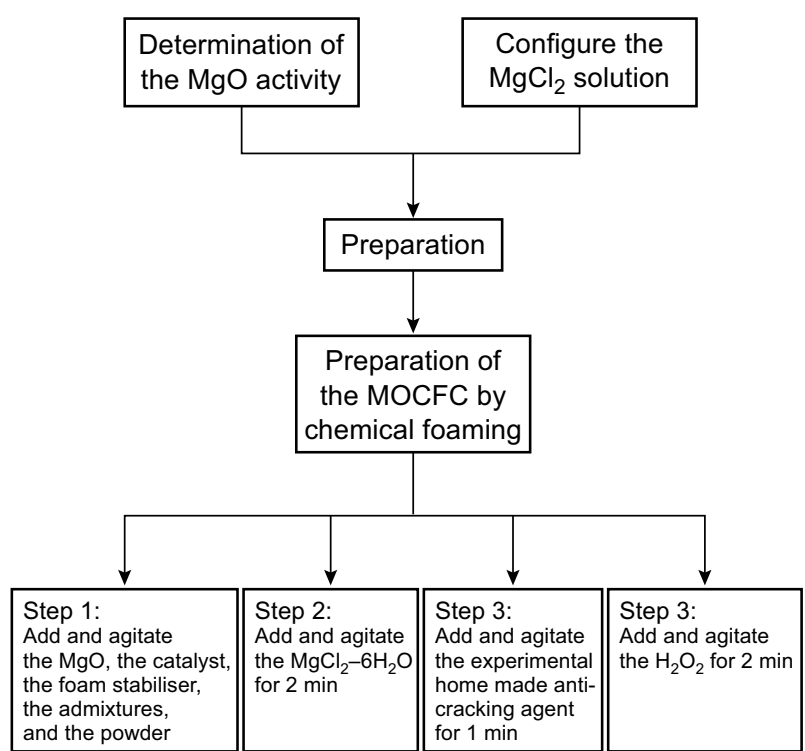

Figure 1. Preparation of the MOCFC.

\section{Specimen analysis}

Compressive strength: a test specimen with dimensions of $100 \times 100 \times 100 \mathrm{~mm}$ was used to measure the strength according to JC/T 1062-2007 "Standard mechanical properties test method for foam concrete blocks" after 3, 7, and 28 days.

Flexural strength: a test piece with dimensions $40 \times$ $\times 40 \times 160 \mathrm{~mm}$ was measured using the tye-10c compression and flexural testing machine after 3, 7, and 28 days aging. Three blocks of the same ratio were measured and averaged.
Dry apparent density: according to the JG/T 2662011 "foam concrete" standard, three X-shaped test pieces were first dried using an electric heating constant temperature drying oven with a working temperature of $60( \pm 5){ }^{\circ} \mathrm{C}$. The mass difference was no more than $1 \mathrm{~g}$ when the samples were measured $4 \mathrm{~h}$ apart. The electric heating constant temperature drying oven was turned off, and the test piece was cooled to room temperature. The drying quality of the sample was accurately measured to $1 \mathrm{~g}$, and the dry density was calculated according to the formula shown in Equation 1.

Thermal conductivity: a test piece of $300 \times 300 \times$ $\times 40 \mathrm{~mm}$, (refer to GB/T 10294-2008 "Measurement of steady-state thermal resistance of thermal insulation materials and related characteristics") was used to measure the thermal conductivity of the Z-shaped test piece. Each test piece was measured three times and averaged.

Volume water absorption rate: according to the JG/T 2357-2016 "Foam concrete product performance test method" standard, the weight of three X-type specimens were measured after drying. The specimens were cooled to room temperature, and water was added to a constant temperature water tank at $20( \pm 5){ }^{\circ} \mathrm{C}$ to ensure the liquid surface was immersed to $1 / 3$ of the height of the test piece. After 24 hours, water was added to ensure $2 / 3$ of the height of the test piece was immersed. After 24 more hours, water was added to exceed $30 \mathrm{~mm}$ of the test piece. The test piece was removed from the water after the 24-hour immersion, the surface moisture was wiped away, and the mass of each test piece was measured. The water absorption rate of the test pieces was then calculated. 
Softening coefficient: according to the JC/T 23572016 "Test method for performance of foam concrete products" standard, three Type X specimens were soaked in water according to the method of the water absorption detection, and then the compressive strength of the three Type X specimens were measured after soaking and softening according to the method of the compressive strength detection. The compressive strength of the Type X specimens was compared without soaking and softening, and the softening coefficient was calculated according to the formula shown in Equation 2.

Porosity: the porosity was calculated according to the empirical Formula 3.

Average pore diameter: the $\mathrm{X}$-shaped test piece $(100 \mathrm{~mm} \times 100 \mathrm{~mm} \times 100 \mathrm{~mm})$ was vertically cut to obtain a surface parallel to the surface of the test piece, and the number of the slurry holes was counted by a ruler, and the average pore size was obtained by dividing the number of pores by $100 \mathrm{~mm}$.

$$
\rho_{0}=M_{0} / V \times 10^{6}
$$

where $\rho_{0}-$ dry density in kilograms per cubic meter $\left(\mathrm{kg} \cdot \mathrm{m}^{-2}\right)$, accurate to $0.1 ; M_{0}$ - weight of the test piece under dry conditions $(\mathrm{g}) ; V$ - volume of the test piece $\left(\mathrm{mm}^{3}\right)$;

$$
R_{w}=F_{c s} / F_{28}
$$

where $R_{w}$-softening coefficient of the test piece, accurate to $0.01 ; F_{c s}$-compressive strength of the test piece after soaking in water (MPa); $F_{28}$ - compressive strength of the test piece after 28 days of aging (MPa)

$$
\varphi=\frac{\rho-\rho_{0}}{\rho} \times 100
$$

where $\varphi$ - porosity of test the piece (\%); $\rho$ - true density of the test piece $\left(\mathrm{kg} \cdot \mathrm{m}^{-3}\right) ; \rho_{0}$ - dry density in kilograms per cubic meter $\left(\mathrm{kg} \cdot \mathrm{m}^{-3}\right)$, accurate to 0.1 ;

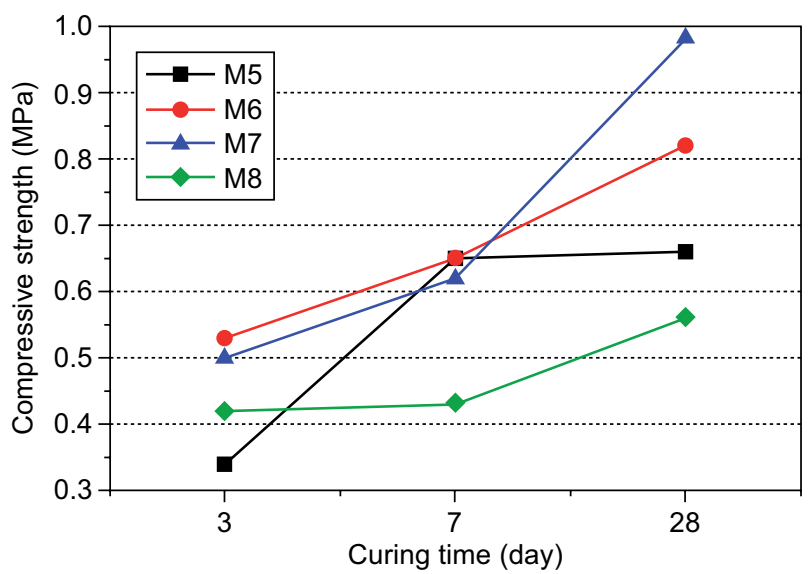

a) compressive strength

\section{RESULTS AND DISCUSSION}

\author{
Molar ratio (M)
}

According to previous studies, the mechanical properties of cement depend on the phase composition, the microscopic appearance of the hydration products of the cement slurry and the raw material ratio. According to Li's report [24], the selection of the $\mathrm{M}$ was limited by the rheology (upper limit) and processability (lower limit) of the mixture. This section primarily studies the effects of the $\mathrm{M}$ on the performance of the MOCFC. The effect of the bulk density on the mechanical properties should be avoided by fixing the dry apparent density (by adjusting the $\mathrm{H}_{2} \mathrm{O}_{2}$ dosage, the dry apparent density of the MOCFC specimens with different Ms is about $220 \mathrm{~kg} \cdot \mathrm{m}^{-3}$ ). The dosage of $\mathrm{H}_{2} \mathrm{O}_{2}$ is shown in Table 3 , the $\mathrm{w} / \mathrm{b}$ is constant at 0.34 . On the basis of determining the concentration of the $\mathrm{MgCl}_{2}$ solution and the activity of the $\mathrm{MgO}$ powder, changing the content of $\mathrm{MgO}$, preparing four different types of test pieces with an $\mathrm{M}$ of $5,6,7$, and 8 , the performance of the MOCFC is measured and compared. Figure 2 shows the effect of the different Ms on the compressive strength and flexural strength of the MOCFC. As can be seen from the figure, when the M is increased from 5 to 7 , the compressive strength of the MOCFC continues to rise from 0.7 $\mathrm{MPa}$ to $1.0 \mathrm{MPa}$, the flexural strength also increases from 0.6 $\mathrm{MPa}$ to $0.8 \mathrm{MPa}$, and the compressive strength and flexural strength increased by $42.85 \%$ and $33.33 \%$, respectively. However, when the $\mathrm{M}$ continues to increase from 7 to 8 , the compressive strength and flexural strength of the MOCFC have a downward trend. Compared with M7, the compressive strength and flexural strength of M8 decreased by $0.4 \mathrm{MPa}$ and $0.2 \mathrm{MPa}$, respectively. The results show that the strength of the MOCFC is affected by different Ms. The possible reason is that the proportion of $5 \mathrm{Mg}(\mathrm{OH})_{2} \cdot \mathrm{MgCl}_{2} \cdot 8 \mathrm{H}_{2} \mathrm{O}(5 \cdot 1 \cdot 8$ phase $)$ is changed due to the change in the M. The $5 \cdot 1 \cdot 8$ phase is the strength phase, which will affect the strength performance of the

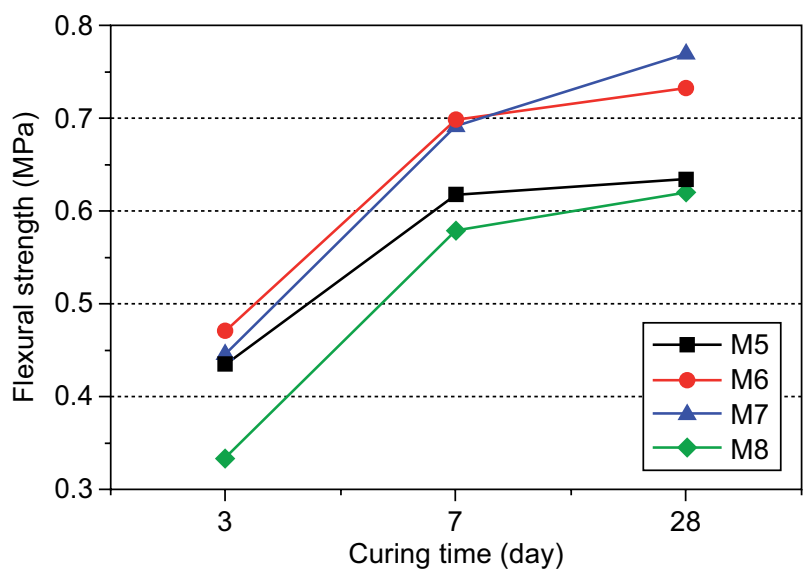

b) flexural strength

Figure 2. Effect of the molar ratio on the MOCFC compressive strength and flexural strength. 
MOCFC [25-26]. It is also possible that changes in the porosity and pore diameter of the slurry lead to changes in the strength properties.

According to the change in strength trend, with respect to the phase composition analysis of the hydration products, Figure 3 shows the X-ray diffraction (XRD) pattern of the MOCFC slurry with different Ms. The results shows that the crystallisation at 28 days is primarily composed of the $5 \cdot 1 \cdot 8$ phase, some residual $\mathrm{MgO}, \mathrm{MgCO}_{3}$, and $\mathrm{SiO}_{2}$ are derived from the raw materials, and a small amount of $\mathrm{Mg}(\mathrm{OH})_{2}$ is generated by the reaction of the excess $\mathrm{MgO}$ and $\mathrm{H}_{2} \mathrm{O}$ in the MOCFC slurry, and there is no new phase generation. The diffraction peak intensity of the $5 \cdot 1 \cdot 8$ phase of M5 in the XRD diagram is significantly higher than that of M6 and M7, the higher the diffraction peak intensity is, the more

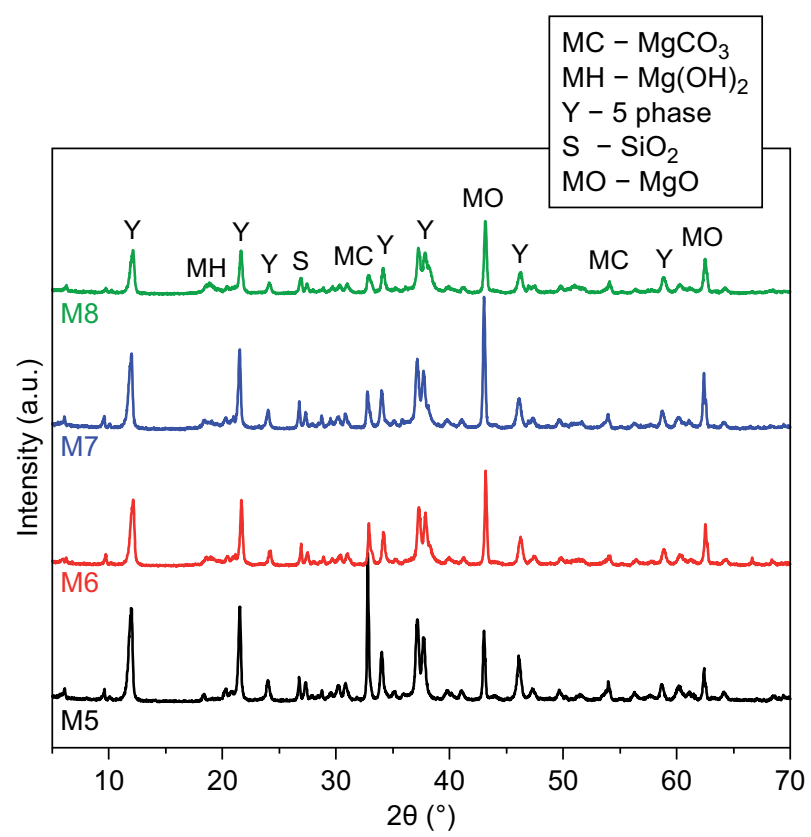

Figure 3. The XRD patterns of the MOC mixtures with the different molar ratios after 28 days.

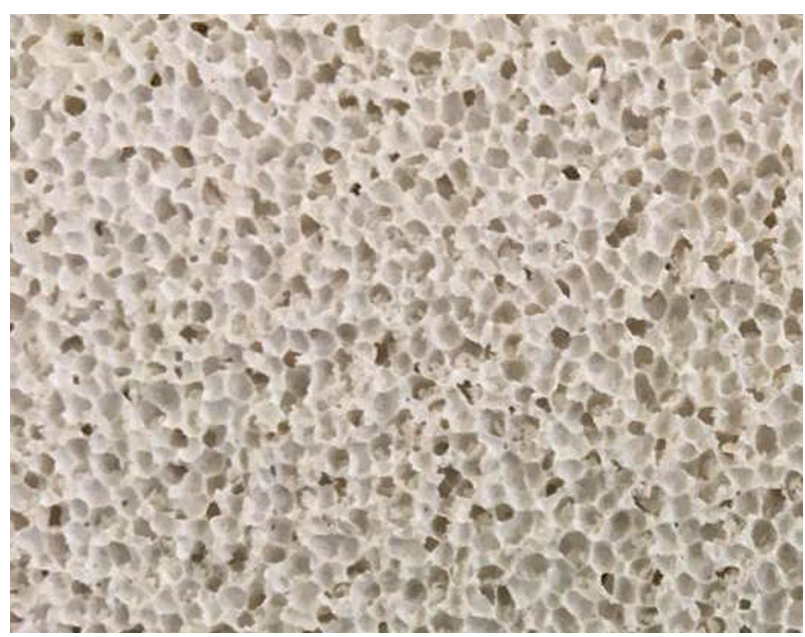

Figure 4. The internal pore structure of the MOCFC.
$5 \cdot 1 \cdot 8$ phases are generated, which is the main strength phase, and the more $5 \cdot 1 \cdot 8$ phases that are produced, the higher the strength is. From the above analysis, it can be concluded that the strength of M5 should be higher than that of M6 and M7. However, it can be found that the strength of M5 is lower than that of M6 and M7 in Figure 2, which is inconsistent with the conclusion of the XRD analysis. It indicates that the variation in the MOCFC strength is not only related to the phase analysis, but it is also related to the porosity and pore diameter. As shown in Figure 4, the reason may be that the foamed concrete is a kind of porous concrete, its internal pores are relatively complex, which is different from ordinary concrete, the pore size and porosity both affect the strength of the foamed concrete.

In order to further study the cause in the strength variation, the porosity and average pore diameter of the slurry were analysed. Table 4 shows the porosity and average pore size of the MOCFC. The table shows that:

- The average pore size of M6 is the same as that of M5, and the porosity of M6 is slightly lower than that of M5, under the same average pore size, it indicates that the lower the porosity is, the internal structure of slurry is denser. The denser the structure is, the greater the strength is, so the strength performance of M6 is higher than that of M5.

- The porosity of M7 is slightly higher than that of M5 and M6, and the average pore size of M7 is lower than that of M5 and M6. Compared to the effect of a slight increase in porosity, the variation of the internal pore structure caused by the average pore size is dominant. The decrease in the average pore size leads to the thickening of the pore wall inside the slurry, which provides support for the MOCFC strength. Therefore, the strength of M7 is higher than that of M5 and M6.

- The porosity and average pore size of M8 are the largest. In addition, the average pore diameter of M8 is larger than the average pore diameter of the other three molar ratios. Therefore, the internal pore structure of the M8 slurry is the loosest and its strength is the lowest.

Table 4 . The relationship between the porosity and average pore size of the different molar ratios at 28 days.

\begin{tabular}{ccc}
\hline$\alpha-\mathrm{MgO} / \mathrm{MgCl}_{2}$ & $\begin{array}{c}\text { Total porosity } \\
(\%)\end{array}$ & $\begin{array}{c}\text { Average pore size } \\
(\mathrm{mm})\end{array}$ \\
\hline 5 & 89.4 & 1.35 \\
6 & 89.1 & 1.35 \\
7 & 90.5 & 1.21 \\
8 & 91.0 & 1.45 \\
\hline
\end{tabular}

In view of the changes in the $M$, the effects on the thermal conductivity, volume water absorption and softening coefficient were studied, the results are shown in Figure 5. When $M$ increases from 5 to 7 , 


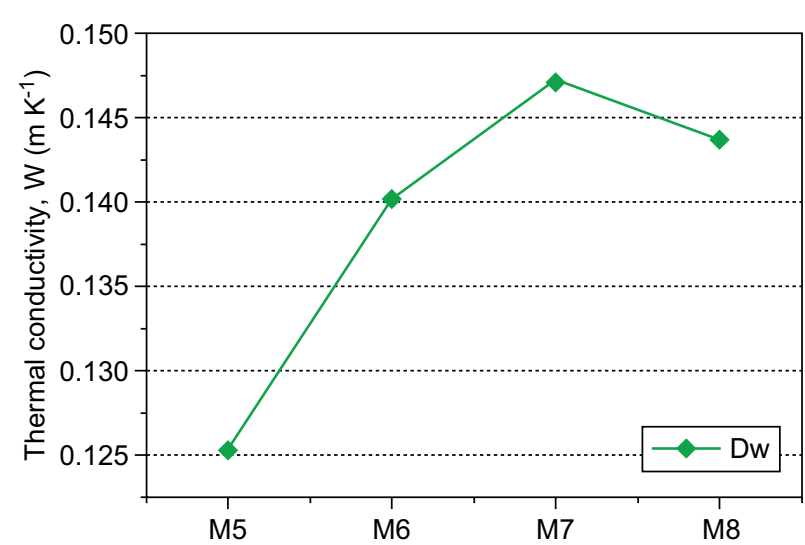

a) thermal conductivity

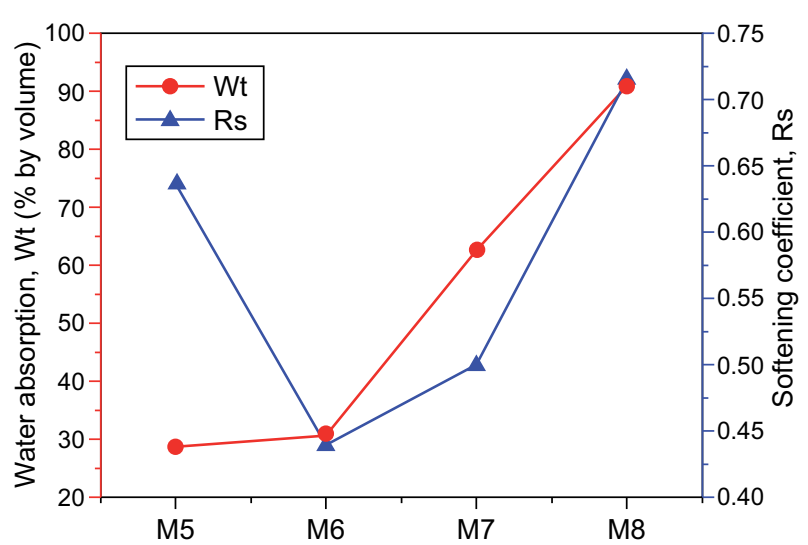

b) volume water absorption and softening coefficient

Figure 5. The effect of the molar ratio on the MOCFC performance.

the thermal conductivity gradually increases from $0.125274 \mathrm{~W} \cdot(\mathrm{m} \cdot \mathrm{K})^{-1}$ to $0.147233 \mathrm{~W} \cdot(\mathrm{m} \cdot \mathrm{K})^{-1}$. Combined with Table 4, it was found that due to the small change in the internal pore structure, compared with the influence on the thermal conductivity of the MOCFC, the change of the raw material caused by the change of the $\mathrm{M}$ has a more obvious influence on the thermal conductivity. This is because with the increase of the $\mathrm{M}$, the amount of $\mathrm{MgCl}_{2} \cdot 6 \mathrm{H}_{2} \mathrm{O}$ required decreases, and the water in the slurry also decreases, in the process of heat conduction, this part of the combined water can absorb less heat, making the thermal conductivity of the MOCFC higher. When the $\mathrm{M}$ increases from 7 to 8 , the thermal conductivity decreases from $0.147233 \mathrm{~W} \cdot(\mathrm{m} \cdot \mathrm{K})^{-1}$ to $0.143697 \mathrm{~W} \cdot(\mathrm{m} \cdot \mathrm{K})^{-1}$. According to Table 4 , the porosity and average pore diameter of M8 are far greater than the other three Ms, compared with the influence of the change in the raw materials on its thermal conductivity, the change in the internal pore structure plays a dominant role in its thermal conductivity. Therefore, the thermal conductivity decreases. With an increase in the $\mathrm{M}$, the volume water absorption increases from $28.92 \%$ to
$91.04 \%$, which shows an upward trend. This is due to the change of the $\mathrm{M}$, which changes the pore structure inside the MOCFC, the porosity as a whole shows an upward trend, which increases the contact area between the material and the water, leading to an increase in the water absorption. With an increase in the $\mathrm{M}$, the softening coefficient first decreases and then increases.

\section{Effects of the $\mathrm{H}_{2} \mathrm{O}_{2}$ dosage}

Bulk density is an important property of foam concrete. The bulk density of foam concrete not only affects its performance, but also determines its application range [27]. The bulk density of foam concrete depends on the dosage of $\mathrm{H}_{2} \mathrm{O}_{2}$. In the process of preparing the MOCFC, $\mathrm{H}_{2} \mathrm{O}_{2}$ acts as a foaming agent, and as the dosage of $\mathrm{H}_{2} \mathrm{O}_{2}$ increases, the foaming process of the slurry gradually becomes faster. To study the effect of the $\mathrm{H}_{2} \mathrm{O}_{2}$ dosage on the strength, the dry apparent density, thermal conductivity, volume water absorption, softening coefficient and microscopic composition of the MOCFC were studied, a molar ratio of $\alpha-\mathrm{MgO} / \mathrm{MgCl}_{2}=6$ was used in the

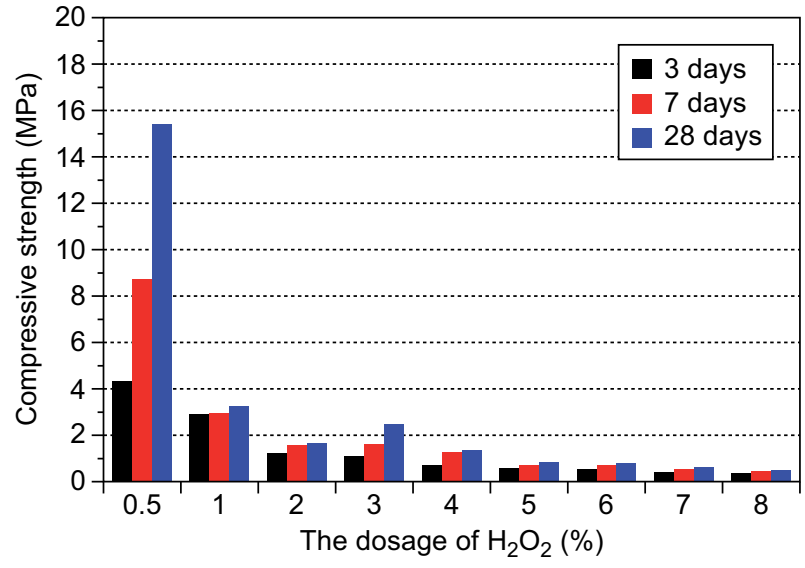

a) compressive strength

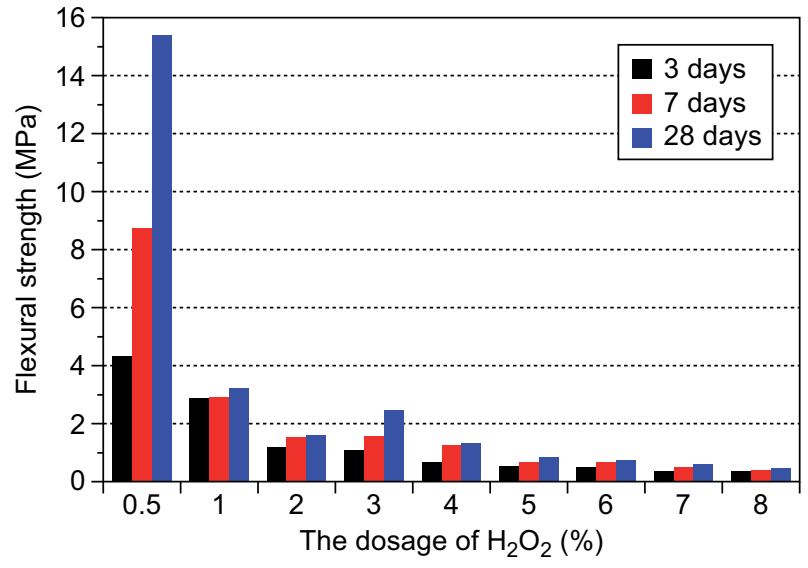

b) flexural strength

Figure 6. The effect of the different $\mathrm{H}_{2} \mathrm{O}_{2}$ dosages on the mechanical properties of the MOCFC at the different curing ages. 
experiment, the $\mathrm{w} / \mathrm{b}$ was constant at 0.34 , and the dosage of $\mathrm{H}_{2} \mathrm{O}_{2}$ varied at $0.5 \%, 1 \%, 2 \%, 3 \%, 4 \%, 5 \%, 6 \%$, $7 \%, 8 \%$ of the LBM powder content. Nine different types of test pieces were generated, and the performance was measured and compared. Figure 6 shows the effect of the $\mathrm{H}_{2} \mathrm{O}_{2}$ dosage on the mechanical properties of the MOCFC at the different curing ages (3, 7, and 28 days). The results show that with an increase in the $\mathrm{H}_{2} \mathrm{O}_{2}$ dosage, the compressive strength and flexural strength of the MOCFC continue to decrease, and when the $\mathrm{H}_{2} \mathrm{O}_{2}$ dosage increases from $0.5 \%$ to $8 \%$, the compressive strength of the 28 day-cured sample decreases from $20 \mathrm{MPa}$ to $0.8 \mathrm{MPa}$ and the flexural strength decreases from $15.4 \mathrm{MPa}$ to $0.5 \mathrm{MPa}$. This is mainly due to the changes in the pore structure inside the sample. With an increase in the $\mathrm{H}_{2} \mathrm{O}_{2}$ dosage, the ratio between the amount of the foam and the slurry volume continues to increase.

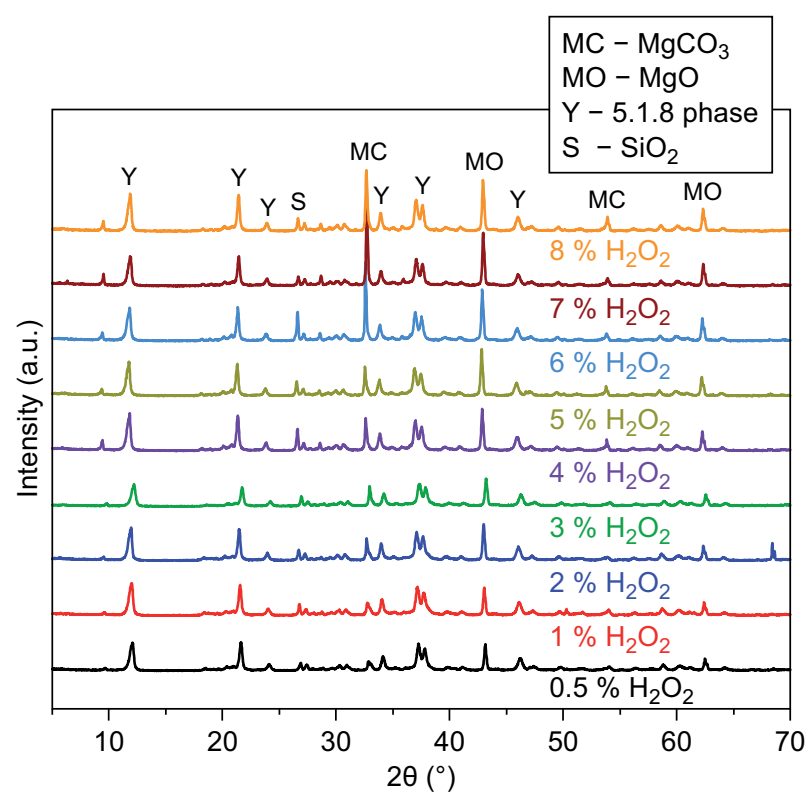

Figure 7. The XRD Patterns of the MOC mixtures with the different $\mathrm{H}_{2} \mathrm{O}_{2}$ dosages at 28days.

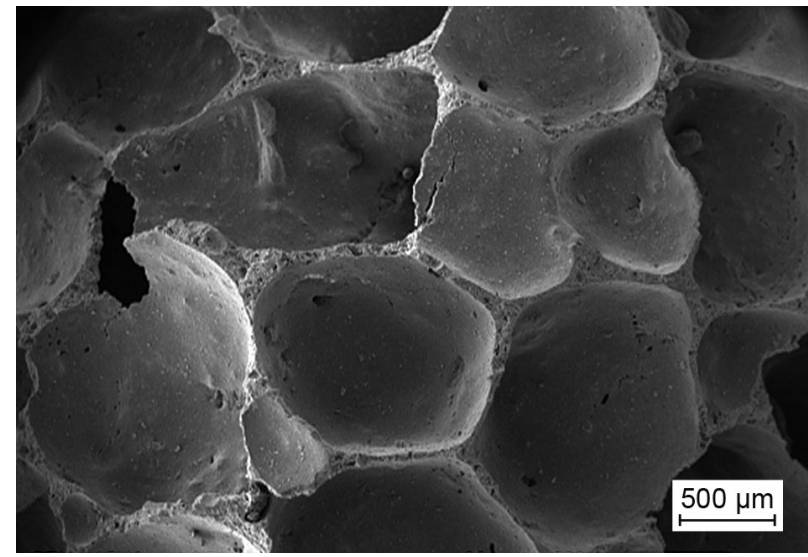

a) $0.5 \% \mathrm{H}_{2} \mathrm{O}_{2}$
After drying, the porosity in the sample increases, the pore wall becomes thinner due to the decrease in the slurry volume, so the strength decreases [28-29].

Based on the change in strength trend, to further study the influence of the $\mathrm{H}_{2} \mathrm{O}_{2}$ dosage on the performance of the MOCFC and figure out the cause of the decrease in strength, the MOCFC phase composition was analysed. Figure 7 shows the XRD pattern of the different $\mathrm{H}_{2} \mathrm{O}_{2}$ dosages on the MOCFC slurry, and the results show that the phases in the MOCFC slurry are still the $5 \cdot 1 \cdot 8$ phase, $\mathrm{MgCO}_{3}, \mathrm{SiO}_{2}$ and $\mathrm{MgO}$, and no new phases are formed. It shows that adding $\mathrm{H}_{2} \mathrm{O}_{2}$ to the MOCFC does not lead to the formation of other hydration products. With the increase in the $\mathrm{H}_{2} \mathrm{O}_{2}$ dosage, the diffraction peak values of the $5 \cdot 1 \cdot 8$ phase and $\mathrm{MgO}$ do not change significantly, there is almost no $\mathrm{Mg}(\mathrm{OH})_{2}$ generation in the slurry. It can be concluded that the phase composition is not the reason for the decrease in the strength.

Figure 8 shows the SEM images of the MOCFC with the different $\mathrm{H}_{2} \mathrm{O}_{2}$ dosages. It was found that the $5 \cdot 1 \cdot 8$ phases do not change its microscopic appearance and are still a six-prism structure, indicating that the change in the $\mathrm{H}_{2} \mathrm{O}_{2}$ dosage does not change the microscopic appearance of the main hydration product in the slurry. According to the SEM X30, when the $\mathrm{H}_{2} \mathrm{O}_{2}$ dosage

Table 5. The relationship between the strength and the porosity of the different $\mathrm{H}_{2} \mathrm{O}_{2}$ dosages at 28 days.

\begin{tabular}{ccc}
\hline $\begin{array}{c}\text { The dosage of } \\
\mathrm{H}_{2} \mathrm{O}_{2}\end{array}$ & $\begin{array}{c}\text { The compressive strength } \\
\text { of 28 days (MPa) }\end{array}$ & $\begin{array}{c}\text { Total porosity } \\
\text { (\%) }\end{array}$ \\
\hline $0.5 \% \mathrm{H}_{2} \mathrm{O}_{2}$ & 20.0 & 40.2 \\
$1 \% \mathrm{H}_{2} \mathrm{O}_{2}$ & 9.8 & 54.9 \\
$2 \% \mathrm{H}_{2} \mathrm{O}_{2}$ & 6.2 & 70.9 \\
$3 \% \mathrm{H}_{2} \mathrm{O}_{2}$ & 4.3 & 78.9 \\
$4 \% \mathrm{H}_{2} \mathrm{O}_{2}$ & 2.8 & 83.2 \\
$5 \% \mathrm{H}_{2} \mathrm{O}_{2}$ & 1.8 & 86.0 \\
$6 \% \mathrm{H}_{2} \mathrm{O}_{2}$ & 1.6 & 88.9 \\
$7 \% \mathrm{H}_{2} \mathrm{O}_{2}$ & 1.5 & 90.8 \\
$8 \% \mathrm{H}_{2} \mathrm{O}_{2}$ & 0.8 & 92.1 \\
\hline
\end{tabular}

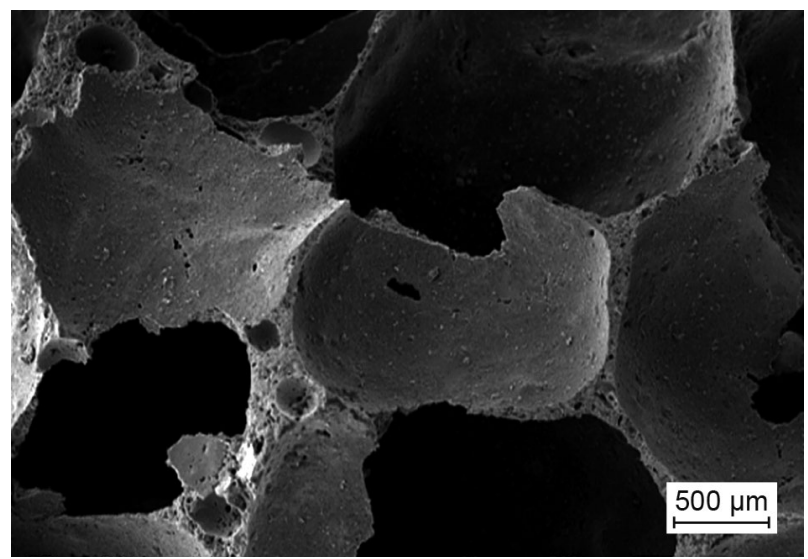

b) $8 \% \mathrm{H}_{2} \mathrm{O}_{2}$

Figure 8. The SEM images of the MOCFC with the different $\mathrm{H}_{2} \mathrm{O}_{2}$ dosages at 28 days. (Continue on next page) 


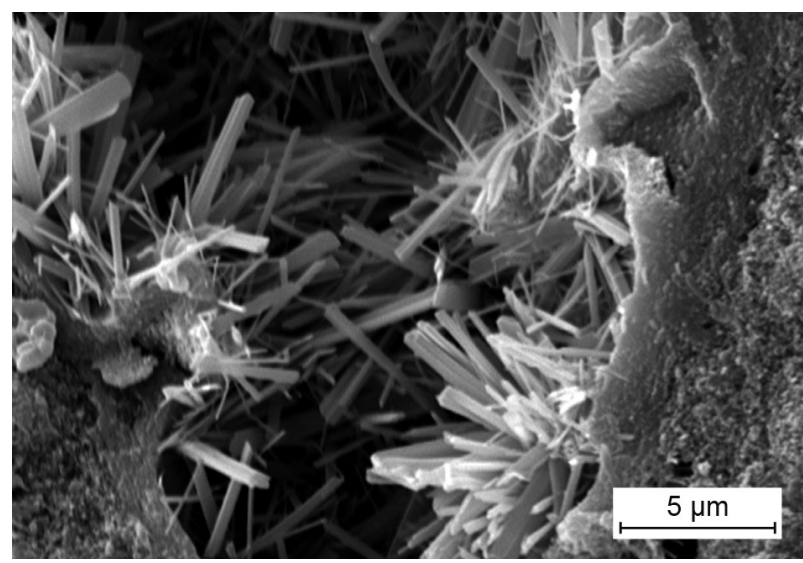

c) $0.5 \% \mathrm{H}_{2} \mathrm{O}_{2}$

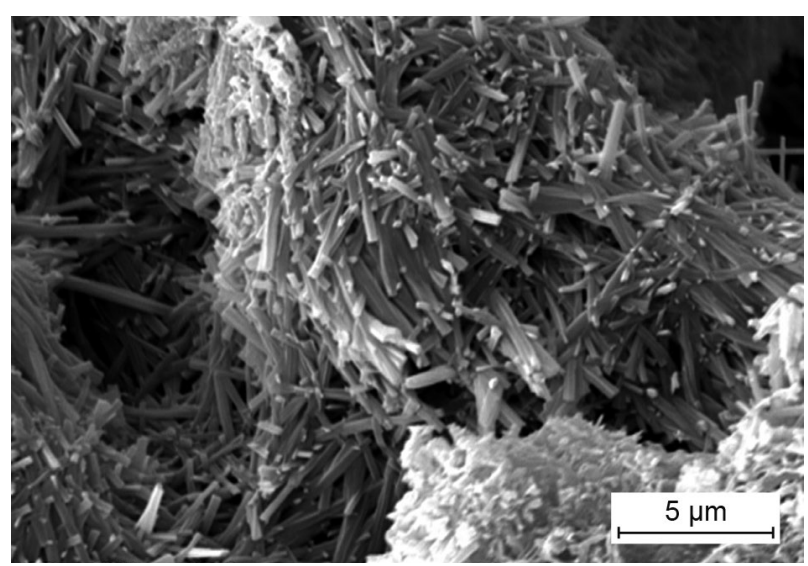

d) $8 \% \mathrm{H}_{2} \mathrm{O}_{2}$

Figure 8. The SEM images of the MOCFC with the different $\mathrm{H}_{2} \mathrm{O}_{2}$ dosages at 28 days.

is $0.5 \%$, the MOCFC slurry is denser and the pore wall is thicker, with an increase in the $\mathrm{H}_{2} \mathrm{O}_{2}$ dosage, when the dosage of $\mathrm{H}_{2} \mathrm{O}_{2}$ is $8 \%$, the pore diameter in the slurry becomes larger and the pore wall becomes thinner. The strength is mainly provided by the support of the pore wall, the thicker the pore wall is, the higher the strength is; on the contrary, the thinner the pore wall is, the lower the strength is [28]. Combined with Table 5, we can see that the porosity of the MOCFC is gradually increasing with an increase in the $\mathrm{H}_{2} \mathrm{O}_{2}$ dosage. This indicates that the change in the internal pore structure of the MOCFC slurry caused by the change in the $\mathrm{H}_{2} \mathrm{O}_{2}$ dosage is the main reason for the decrease in the mechanical strength.

Figure 9a shows the effect of the $\mathrm{H}_{2} \mathrm{O}_{2}$ dosage on the thermal insulation properties of the MOCFC. The results show that the dry apparent density and the thermal conductivity of the MOCFC continues to decrease with an increase in the $\mathrm{H}_{2} \mathrm{O}_{2}$ dosage. The dry apparent density of the MOCFC decreases from $1037.5 \mathrm{~kg} \cdot \mathrm{m}^{-3}$ to $189.4 \mathrm{~kg} \cdot \mathrm{m}^{-3}$ and the thermal conductivity decreases from $0.454643 \mathrm{~W} \cdot(\mathrm{m} \cdot \mathrm{K})^{-1}$ to $0.115939 \mathrm{~W} \cdot(\mathrm{m} \cdot \mathrm{K})^{-1}$. This is because $\mathrm{H}_{2} \mathrm{O}_{2}$ acts as a foaming agent, as the dosage of the foaming agent increases, more micro-bubbles

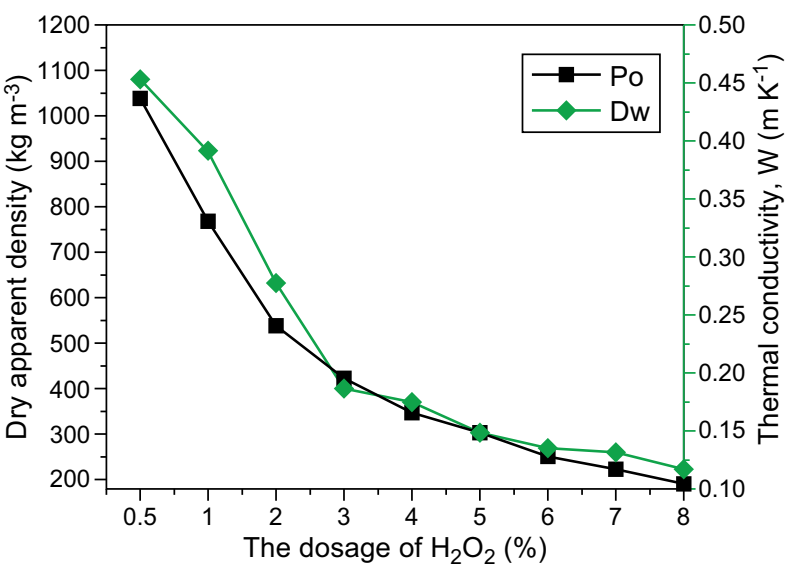

a) dry apparent density and thermal conductivity are produced by high-speed foam production, then more micro-closed bubbles are produced in the cement slurry, making the volume of the MOCFC increase, so the dry apparent density decreases. The smaller the dry apparent density of the foam concrete is, the lower the proportion of solid phase is, the smaller the proportion of the heat transferred by heat conduction is, and the lower the efficiency of the heat transfer is. Therefore, the thermal conductivity is reduced, the thermal insulation properties are improved. Figure $9 \mathrm{~b}$ shows the effect of the $\mathrm{H}_{2} \mathrm{O}_{2}$ dosage on the water resistance of the MOCFC. As can be seen from the figure, when the $\mathrm{H}_{2} \mathrm{O}_{2}$ dosage increases from $0.5 \%$ to $8 \%$, the volume of the water absorption of the MOCFC continues to rise, from $2.09 \%$ to $67.18 \%$, and the softening coefficient on the whole shows a downward trend, from 0.91 to 0.4 . Combined with Table 5 and the SEM images in Figure 8, it was found that the pore structure of the MOCFC changes significantly with the change in the $\mathrm{H}_{2} \mathrm{O}_{2}$ dosage. When the $\mathrm{H}_{2} \mathrm{O}_{2}$ dosage increases, the porosity increases, the pore wall becomes thin, and the pore structure becomes loose, which increases the contact area between the material and the water, leading to an increase in the water

Figure 9. The effect of the $\mathrm{H}_{2} \mathrm{O}_{2}$ dosage on the MOCFC performance. 
absorption, and accelerating the decomposition rate of the hydration crystal products meeting the water, so the strength decreases and the water resistance becomes poor. In conclusion, the incorporation of $\mathrm{H}_{2} \mathrm{O}_{2}$ improves the thermal insulation performance of the MOCFC and restricts the development of its mechanical properties and water resistance.

\section{Effects of the FAdosage}

To study the effects of the FA dosage on the performance of the MOCFC, the experiment used a molar ratio of $\alpha-\mathrm{MgO} / \mathrm{MgCl}_{2}=6$, the $\mathrm{H}_{2} \mathrm{O}_{2}$ dosage was $5 \%$ of the LBM powder content, and the FA dosage varied at $0 \%, 5 \%, 10 \%, 15 \%, 20 \%$ of the LBM powder content, five different types of test pieces were prepared with a w/b of 0.34 . By measuring the MOCFC strength, dry apparent density, thermal conductivity, volume water absorption, softening coefficient, and other properties, using the origin to draw, analyse, and summarise the data, the effects of the FA dosage on the MOCFC performance were studied. Figure 10 shows the influence of the different FA dosages on the mechanical properties of the MOCFC at the different curing ages (3, 7, 28 days). The results show that with an increase in the FA dosage, the compressive strength and flexural strength of the MOCFC develop in a wavy trend. Compared with the $0 \%$ FA test piece, the compressive and flexural strength of the four different types of specimens mixed with the FA decreases, indicating that the FA limits the development of the MOCFC's mechanical properties. The possible reason is that with an increase in the FA dosage, the proportion of the $\mathrm{MgO}$ powder content correspondingly decreases, the strength phase of the $5 \cdot 1 \cdot 8$ phase crystal is reduced, which results in a reduction in the mechanical properties of the MOCFC. It is also possible that the addition of the FA changes the pore structure inside the slurry, causing the MOCFC bulk density to decrease, thus resulting in a decrease in the MOCFC strength.

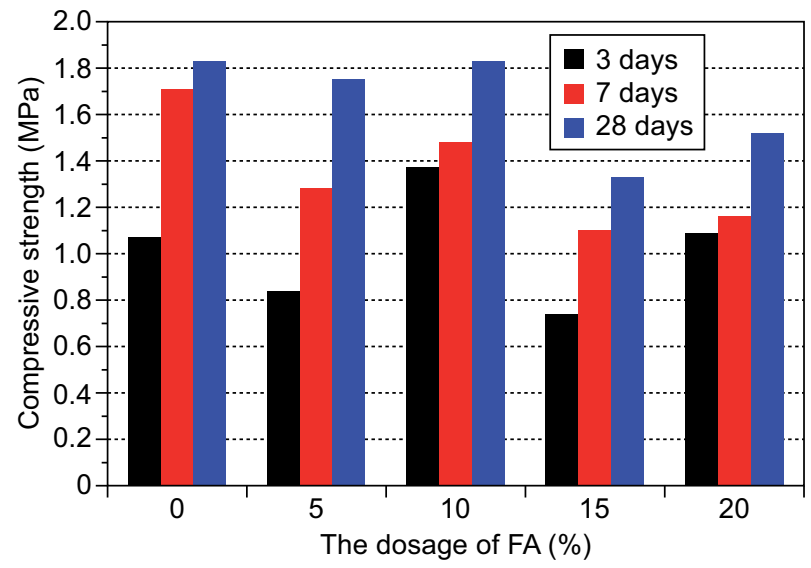

a) compressive strength
Based on the change in the strength trend, the phase composition of its hydration products was analysed. Figure 11 shows the XRD pattern of the MOCFC slurry with the different FA dosages. It can be seen, from Figure 11, that with an increase in the FA dosage, the phase of the MOCFC slurry is still the $5 \cdot 1 \cdot 8$ phase, $\mathrm{MgCO}_{3}$, $\mathrm{SiO}_{2}$ and $\mathrm{MgO}$, and there is no new phase generation. It shows that adding the FA to the MOCFC does not lead to the formation of other hydration products. The diffraction peak values of the $5 \cdot 1 \cdot 8$ phase and $\mathrm{MgO}$ do not significantly change under the different FA dosages. It indicates that an increase in the FA dosage has little influence on the decrease of the $\mathrm{MgO}$ powder content and the $5 \cdot 1 \cdot 8$ phase crystal. Therefore, the influence on the strength performance remains to be proved.

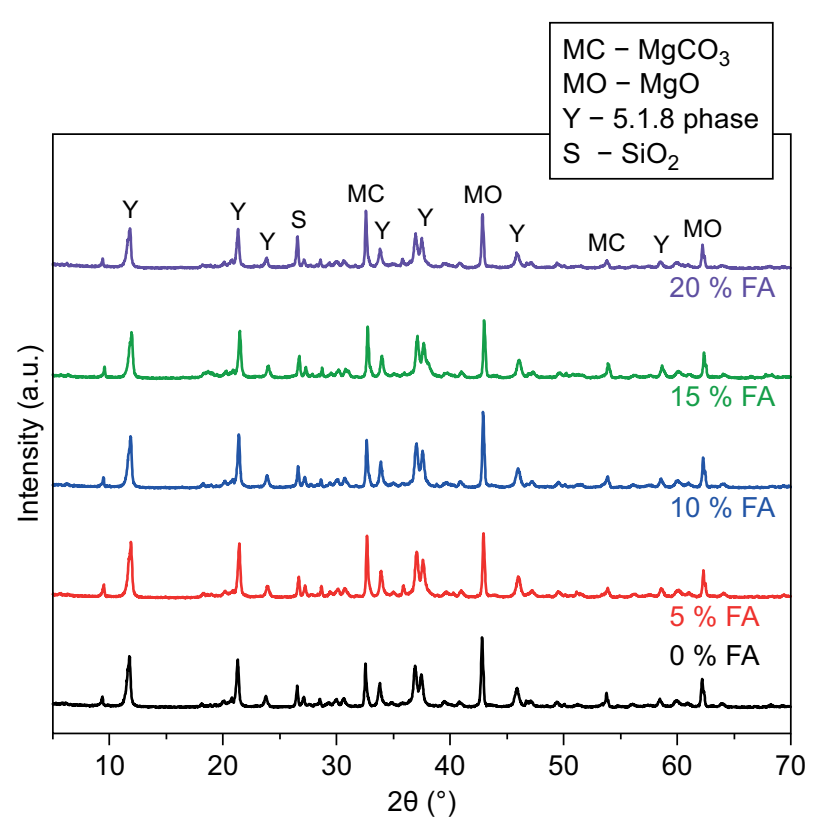

Figure 11. The XRD Patterns of the MOC mixtures with the different FA dosages at 28 days.

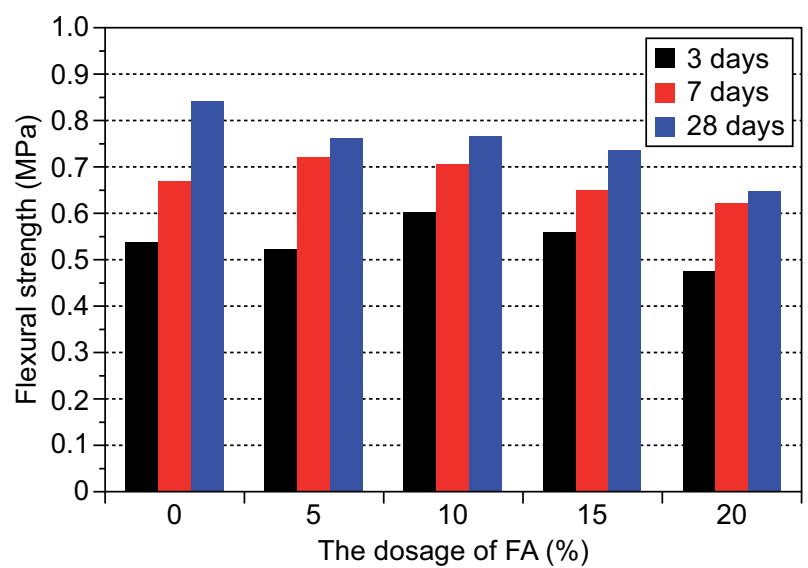

b) flexural strength

Figure 10. The effect of the FA dosage on the compressive strength and the flexural strength of the MOCFC. 
According to the influence of the different FA dosages on the MOCFC microscopic appearance, the SEM images were analysed. Figure 12 shows the SEM images of the MOCFC with the different FA dosages, where it was found that the $5 \cdot 1 \cdot 8$ phases do not change its microscopic appearance and are still a six-prism structure, indicating that the change in the FA dosage does not change the microscopic appearance of the main hydration product in the slurry. Combined with Table 6, we can know that the porosity of the MOCFC is

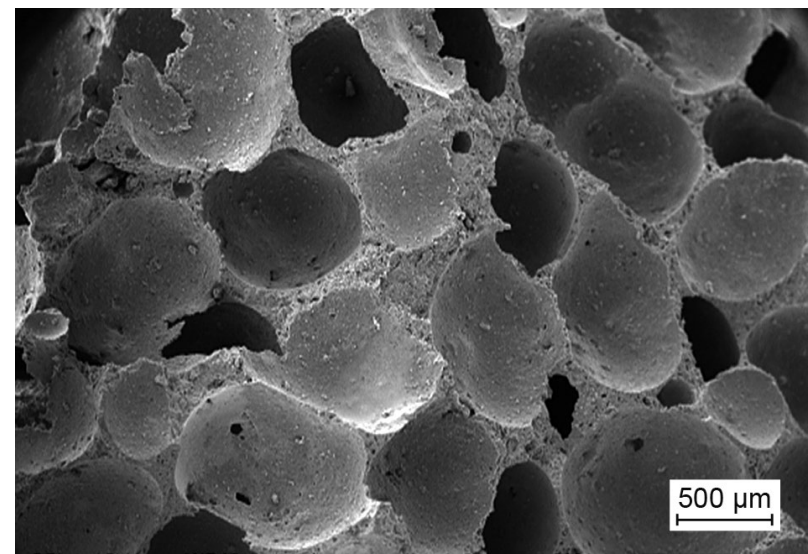

a) $0 \% \mathrm{FA}$

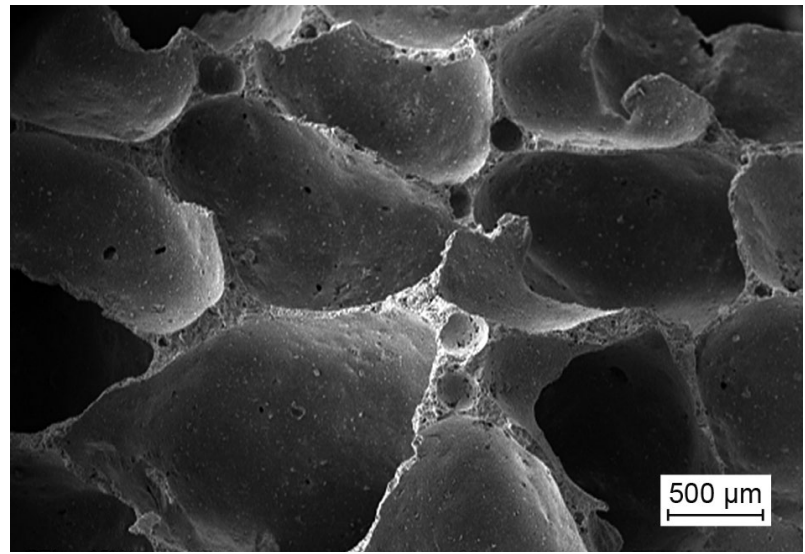

c) $5 \% \mathrm{FA}$

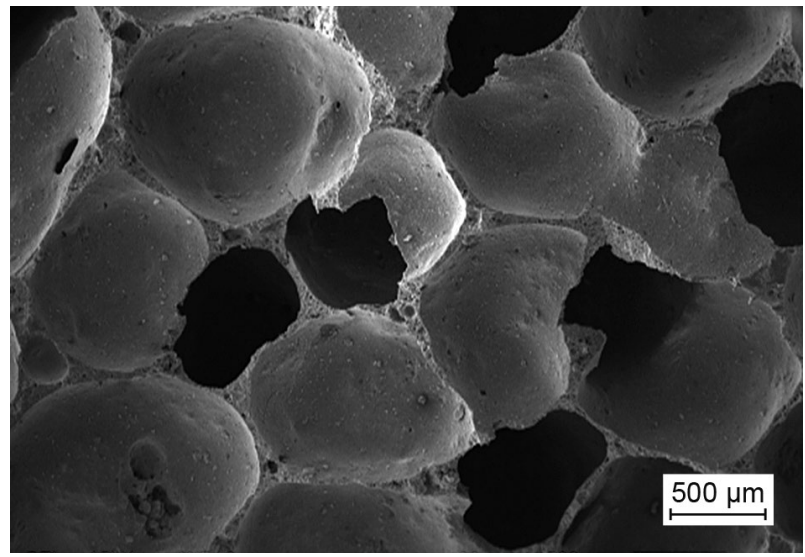

e) $20 \% \mathrm{FA}$
Table 6 . The relationship between the strength and the porosity of the different FA dosages at 28 days.

\begin{tabular}{ccc}
$\begin{array}{c}\text { The dosage of } \\
\text { FA }\end{array}$ & $\begin{array}{c}\text { The compressive strength } \\
\text { of 28 days (MPa) }\end{array}$ & $\begin{array}{c}\text { Total porosity } \\
(\%)\end{array}$ \\
\hline $0 \% \mathrm{FA}$ & 1.8 & 86.0 \\
$5 \% \mathrm{FA}$ & 1.7 & 88.6 \\
$10 \% \mathrm{FA}$ & 1.8 & 89.3 \\
$15 \% \mathrm{FA}$ & 1.3 & 89.5 \\
$20 \% \mathrm{FA}$ & 1.5 & 90.2 \\
\hline
\end{tabular}

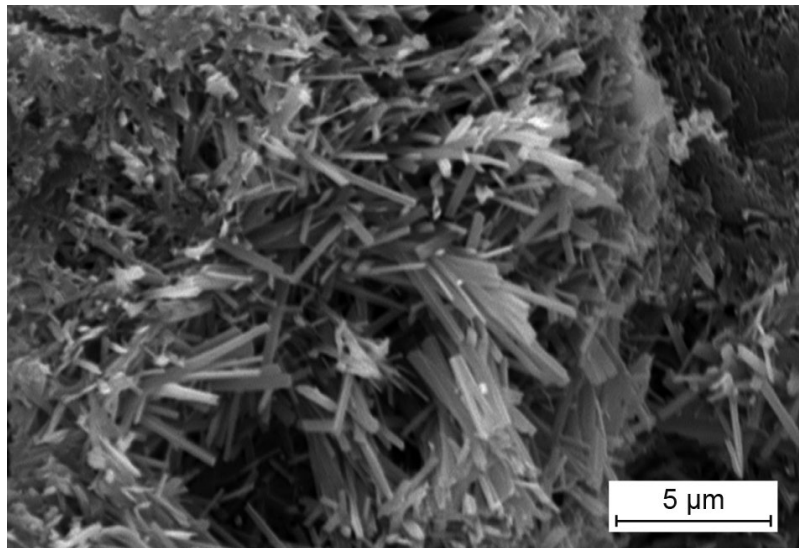

b) $0 \% \mathrm{FA}$

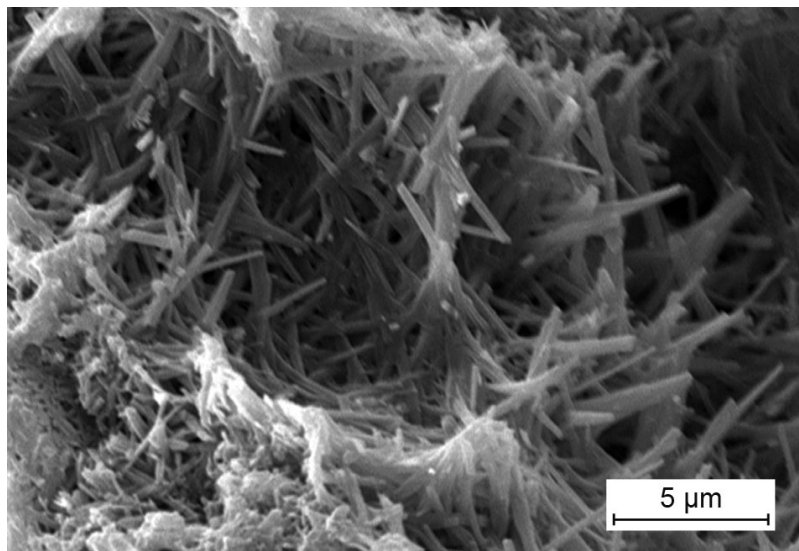

d) $5 \% \mathrm{FA}$

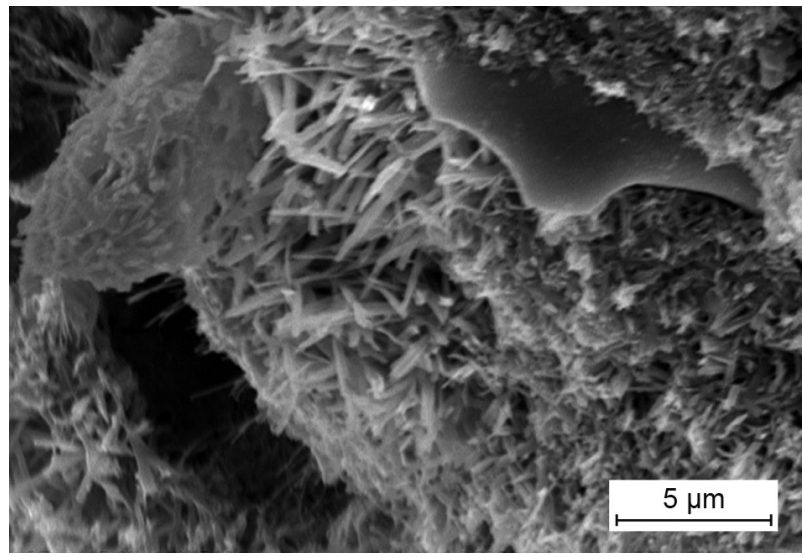

f) $20 \% \mathrm{FA}$

Figure 12. The SEM images of the MOCFC with the different FA dosages at 28 days. 
gradually increasing with an increase in the FA dosage. Together with the "filling effect" and "micro-aggregate effect" of the FA, a large number of fine FA particles will be filled into the cement and the pores of the hydration products in the FA clinker minerals, allowing the larger pores in the foam concrete test piece to be divided into a large number of fine pores and refine the pore diameter of the test piece [30-31]. This leads to changes in the internal pore structure of the MOCFC slurry. Therefore, it can be concluded that the reason for the decline in the MOCFC strength is related to the pore structure inside the slurry.

Figure 13a shows the effect of the FA dosage on the thermal insulation properties of the MOCFC. As the FA dosage increases, the MOCFC dry apparent density decreases from $301.3 \mathrm{~kg} \cdot \mathrm{m}^{-3}$ to $231.9 \mathrm{~kg} \cdot \mathrm{m}^{-3}$, the thermal conductivity shows a downward trend as a whole, decreasing from $0.1456 \mathrm{~W} \cdot(\mathrm{m} \cdot \mathrm{K})^{-1}$ to $0.1285 \mathrm{~W} \cdot(\mathrm{m} \cdot \mathrm{K})^{-1}$. This is because the density of the FA is less than the density of $\mathrm{MgO}$ (as can be seen from the raw materials), when $\mathrm{MgO}$ is replaced by an equivalent amount of FA, the volume of the test piece will increase, so the dry apparent density will decrease. The smaller the dry apparent density of the foam concrete is, the lower the proportion of the solid phase is, the smaller the proportion of the heat transferred by the heat conduction is, and the lower the efficiency of the heat transfer is. Therefore, the thermal conductivity is reduced. An increase in the FA dosage reduces the thermal conductivity of the MOCFC, which is beneficial to improve the MOCFC's thermal insulation performance. Figure $13 \mathrm{~b}$ shows the effect of the FA dosage on the water resistance of the MOCFC. It can be found from the figure that the volume water absorption of the sample with the FA added is higher than that of the sample without the FA. This is due to the incorporation of the FA, which changes the pore structure inside the MOCFC, which causes the porosity to rise, increases the contact area between the material and water, and causes the water absorption to rise. The softening coefficient first increased and then decreased, when $5 \%$ FA was

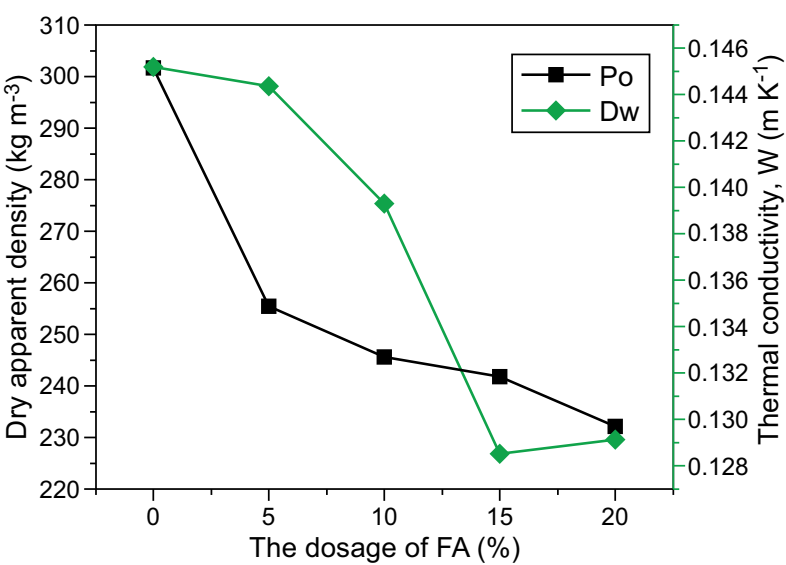

a) dry apparent density and thermal conductivity added, the softening coefficient increased from 0.57 to 0.58 , when the FA dosage increased from $5 \%$ to $20 \%$, the softening coefficient continued to decrease from 0.58 to 0.38 . Which shows that the addition of the FA leads to the poor water resistance of the MOCFC. In summary, the incorporation of FA improves the thermal insulation properties of the MOCFC and limits the development of its mechanical properties and water resistance.

\section{Effects of the KDP dosage}

To study the effect of the KDP dosage on the strength, dry apparent density, thermal conductivity, volume water absorption and softening coefficient of the MOCFC, a molar ratio of $\alpha-\mathrm{MgO} / \mathrm{MgCl}_{2}=6$ was used in the experiment, the dosage of $\mathrm{H}_{2} \mathrm{O}_{2}$ was $5 \%$ of the LBM powder content, the water-to-binder ratio was constant at 0.34 , and the dosage of the KDP varied at $0 \%, 0.5 \%$, $1 \%, 1.5 \%$ of the LBM powder content. Four different types of test pieces were generated, and the performance was measured and compared. Figure 14 shows the effects of the different KDP dosages on the compressive strength and flexural strength of the MOCFC. It can be seen from the figure that the early strength of the four different types of test pieces changes rapidly, the compressive strength after 7 days of curing is about $80 \%$ of the compressive strength after 28 days of curing, the rate of change in the strength in the later period is slow, and the overall increase is relatively small, these observations reflect the characteristics of the early strength of the MOCFC. With an increase in the KDP dosage, the compressive strength and flexural strength of the MOCFC are reduced when compared with the samples without the KDP. When adding $1.5 \% \mathrm{KDP}$, the compressive strength and flexural strength of the MOCFC with a curing age of 28 days were the lowest, $0.9 \mathrm{MPa}$ and $0.4 \mathrm{MPa}$, respectively, and compared with the control samples, the decrease was $53 \%$ and $49.2 \%$, respectively. This indicates that the addition of KDP will constrain the strength development of the MOCFC and have an adverse effect on its strength.

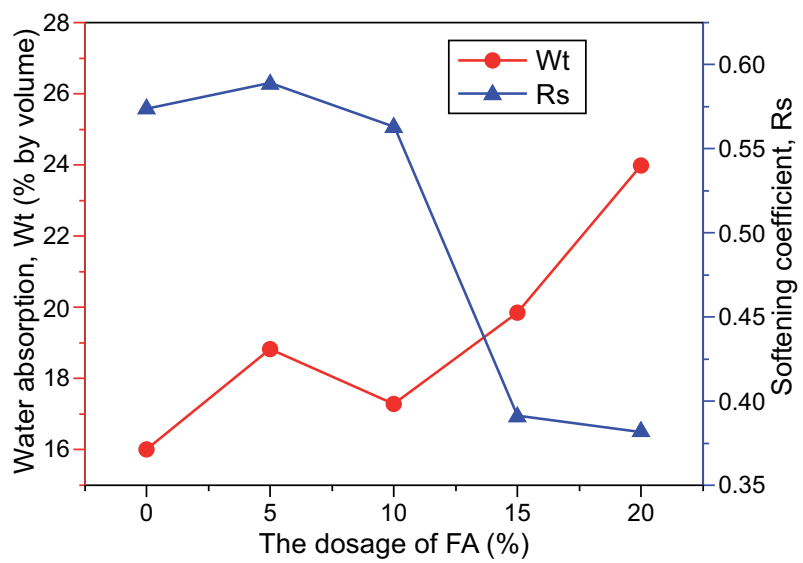

b) volume water absorption and softening coefficient

Figure 13. The effect of the FA dosage on the MOCFC performance. 


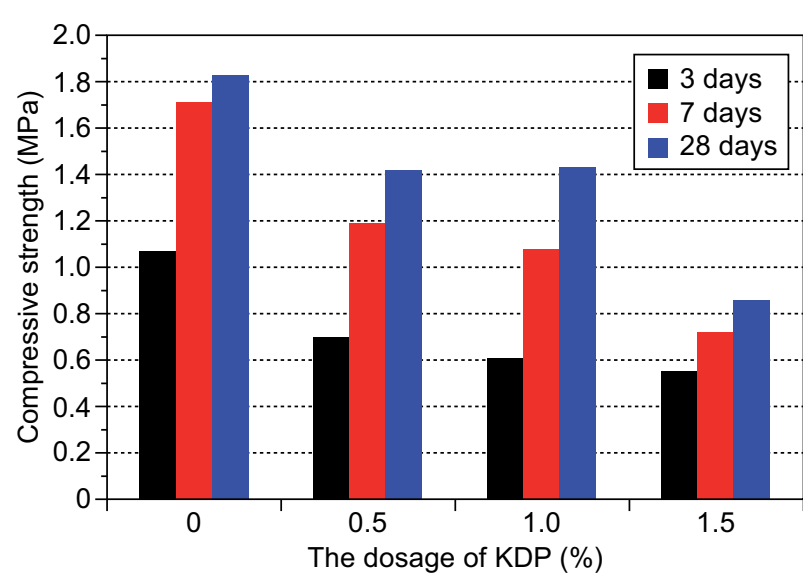

a) compressive strength

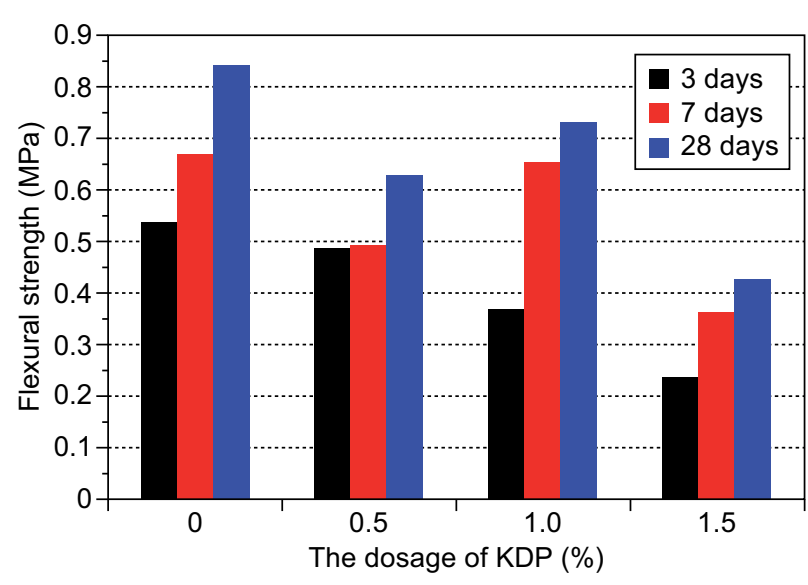

b) flexural strength

Figure 14. The effect of the KDP dosage on the compressive strength and flexural strength of the MOCFC.

The possible reason is that the addition of KDP changes the phase composition and the microscopic appearance of the MOCFC, it is also possible that the addition of KDP changes the pore structure inside the slurry, resulting in a decrease in the bulk density of foamed concrete.

To further explore the reasons for the strength reduction, an XRD phase analysis of the KDP with the different dosages was carried out. Figure 15 shows the XRD pattern of the MOCFC with different KDP dosages. It can be seen from Figure 15 that with an increase in the KDP dosage, the phase of the MOCFC slurry is still the $5 \cdot 1 \cdot 8$ phase, $\mathrm{MgCO}_{3}, \mathrm{SiO}_{2}$ and $\mathrm{MgO}$, and there is no new phase generation. It shows that adding the KDP to the MOCFC does not lead to the formation of other hydration products. With an increase in the KDP dosage, the diffraction peak values of the $5 \cdot 1 \cdot 8$ phase and $\mathrm{MgO}$ do not change significantly. It can be concluded that the phase composition is not the primary reason for the decrease in the strength.

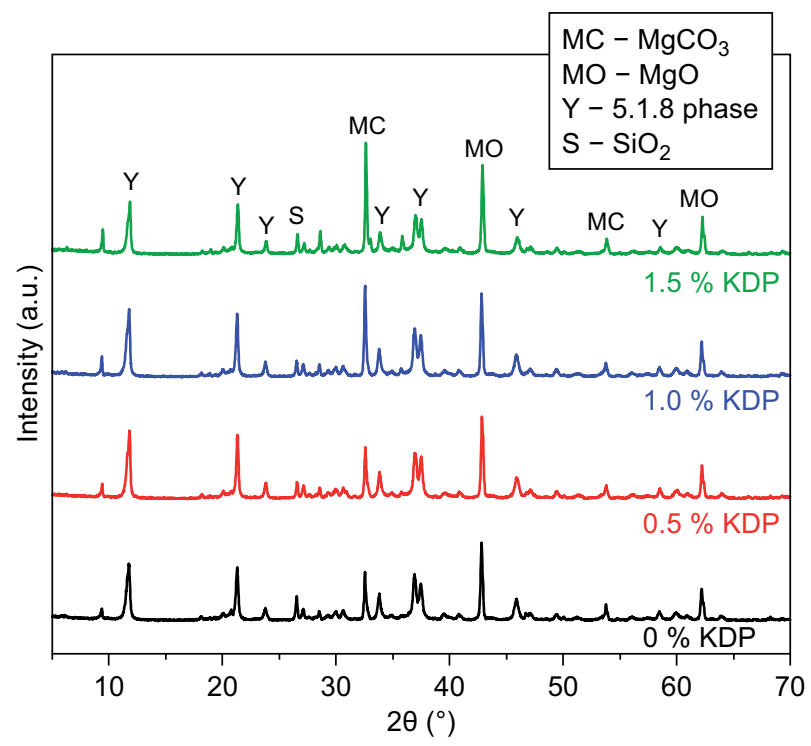

Figure 15. The XRD patterns of the MOC mixtures with the different KDP dosages at 28 days.
According to the influence of the different KDP dosages on the microscopic appearance of the MOCFC, the four different types of specimens with $0 \% \mathrm{KDP}$, $0.5 \% \mathrm{KDP}, 1 \% \mathrm{KDP}$, and $1.5 \% \mathrm{KDP}$ were analysed by the SEM images. Select a few pictures with an obvious effect for analysis. It can be seen from Figure 16 that the $5 \cdot 1 \cdot 8$ phase of the $0 \% \mathrm{KDP}, 0.5 \% \mathrm{KDP}$, and $1.5 \% \mathrm{KDP}$ is still a six-prism structure, indicating that the change in the KDP dosage does not change the microscopic appearance of the main hydration product in the slurry. It can be seen from Table 7 that the porosity increases gradually with an increase in the KDP dosage. This indicates that the change in the internal pore structure of the MOCFC slurry caused by the change in the KDP dosage is the main reason for the decrease in the mechanical strength.

Table 7. The relationship between the strength and the porosity of the different KDP dosage at 28 days.

\begin{tabular}{ccc}
\hline $\begin{array}{c}\text { The dosage of } \\
\text { KDP }\end{array}$ & $\begin{array}{c}\text { The compressive strength } \\
\text { of 28 days (MPa) }\end{array}$ & $\begin{array}{c}\text { Total porosity } \\
(\%)\end{array}$ \\
\hline $0 \% \mathrm{KDP}$ & 1.8 & 86.0 \\
$0.5 \% \mathrm{KDP}$ & 1.4 & 87.9 \\
$1.0 \% \mathrm{KDP}$ & 1.4 & 88.4 \\
$1.5 \% \mathrm{KDP}$ & 0.9 & 89.2 \\
\hline
\end{tabular}

In view of the changes in the KDP dosage, the effects on the dry apparent density, thermal conductivity, volume water absorption and softening coefficient were studied, the results are shown in Figure 17. With an increase in the KDP dosage, when compared with the $0 \% \mathrm{KDP}$, the dry apparent density and thermal conductivity of the MOCFC decrease rapidly when $0.5 \% \mathrm{KDP}$ is added, the volume water absorption increases rapidly, and the softening coefficient decreases. The reduction of the dry apparent density is due to the addition of the KDP, which causes the solution to be weakly alkaline and accelerates the decomposition 
rate of $\mathrm{H}_{2} \mathrm{O}_{2}$, leading to an increase in the porosity, so the dry apparent density decreases. Due to the small dosage of the KDP, compared with the water resistance of the MOCFC, it was improved by KDP, the internal pore structure of MOCFC changes more obviously and plays a dominant role in the water resistance of the MOCFC. The rapid decline of the bulk density indicates that the porosity and pore size are greatly increased, the pore structure becomes loose, which increases the contact area between the materials and the water and accelerates the rate of decomposition of the hydration crystal product meeting the water, so the strength is reduced and the water resistance is poor. As the bulk density decreases, the thermal conductivity decreases, indicating that the thermal insulation performance is improved. When the $\mathrm{KDP}$ dosage increases from $0.5 \%$ to $1.5 \%$, the dry apparent density and thermal conductivity of the MOCFC decrease slowly, the volume

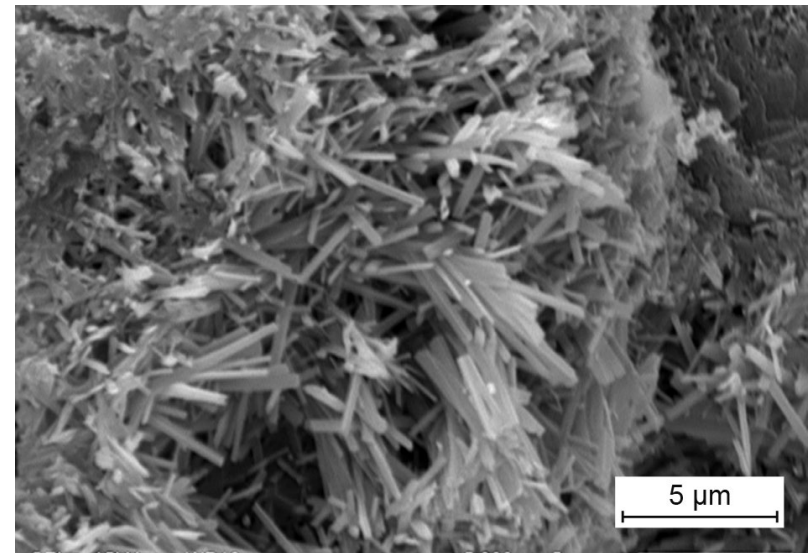

a) $0 \% \mathrm{KDP}$

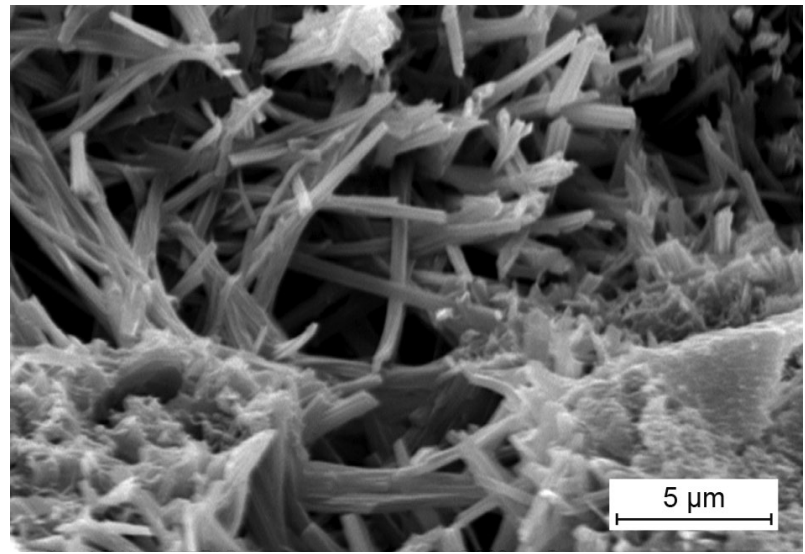

c) $0.5 \% \mathrm{KDP}$

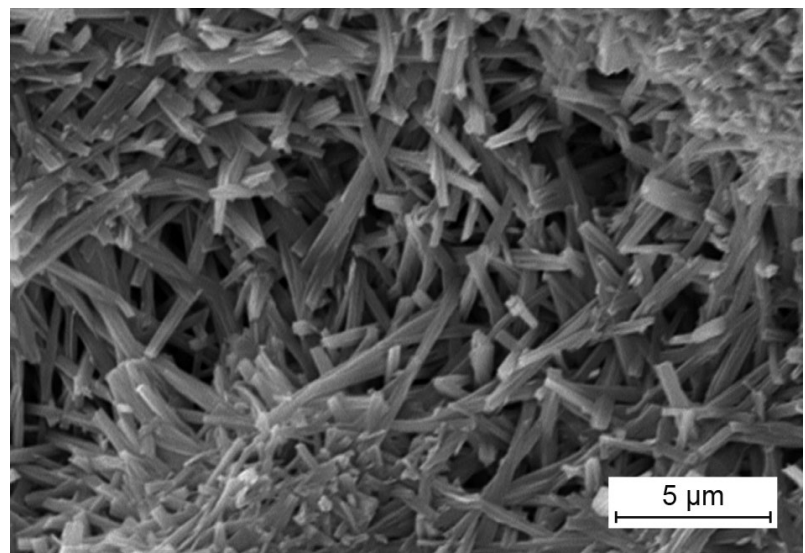

e) $1.5 \% \mathrm{KDP}$

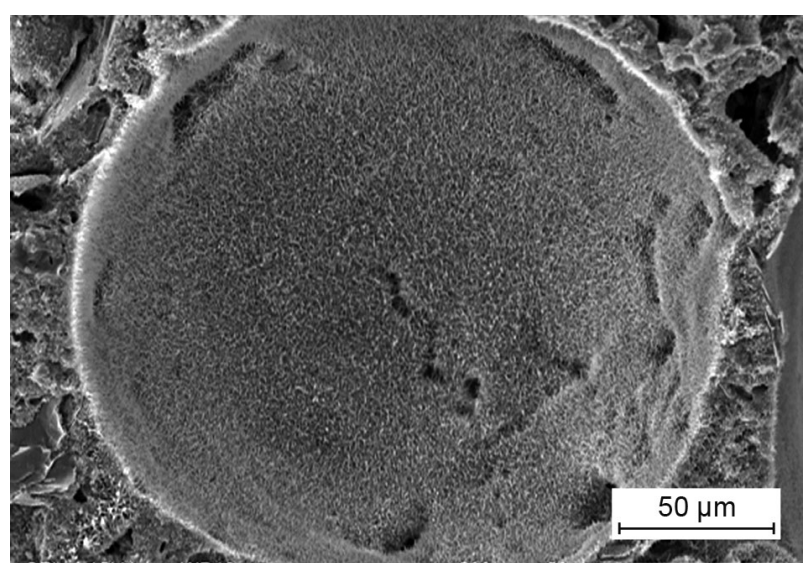

b) $0 \% \mathrm{KDP}$

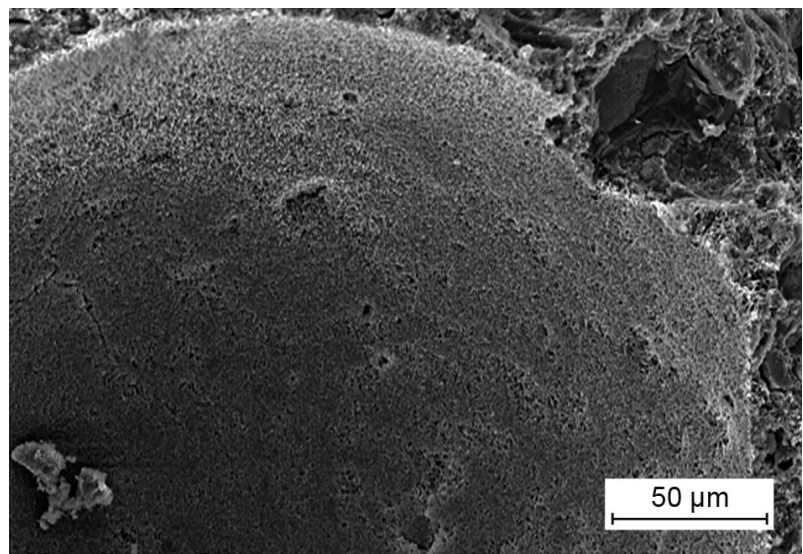

d) $0.5 \% \mathrm{KDP}$

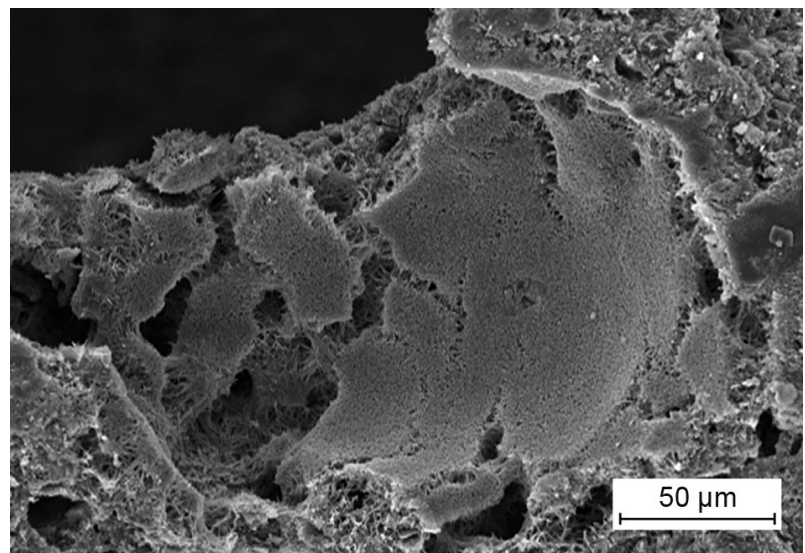

f) $1.5 \% \mathrm{KDP}$

Figure 16. The SEM images of the MOCFC with the different KDP dosages at 28 days. 


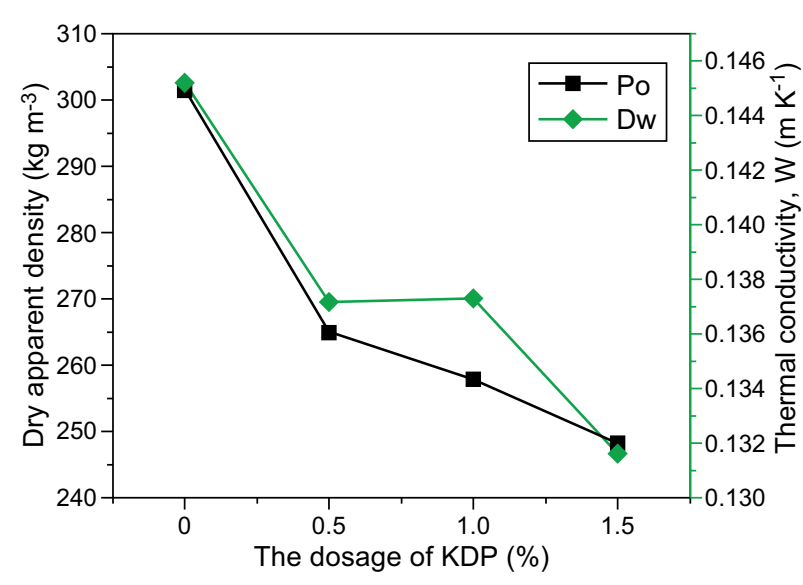

a) dry apparent density and thermal conductivity

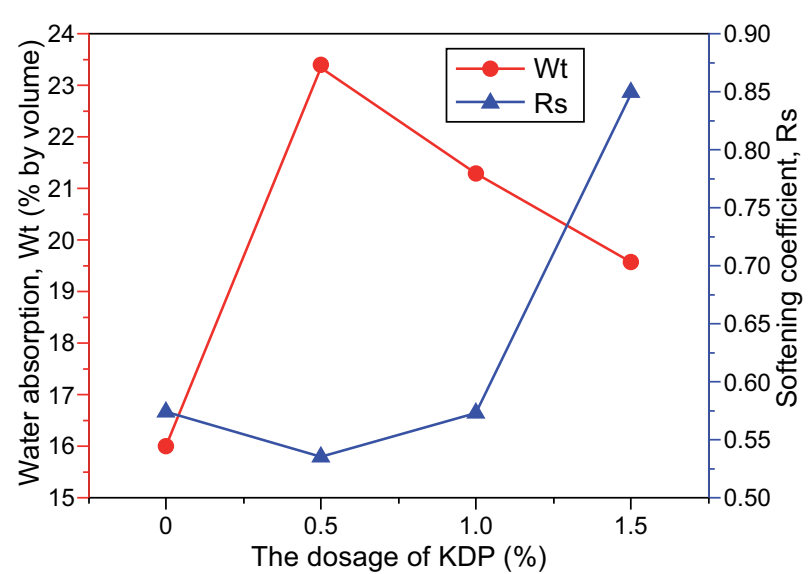

b) volume water absorption and softening coefficient

Figure 17. The effect of the KDP dosage on the MOCFC performance.

water absorption decreases, and the softening coefficient increases. The bulk density tends to decrease slightly, the thermal conductivity decreases, indicating that the thermal insulation performance is further improved. The decrease in the bulk density indicates that the porosity and pore size increase, but the water absorption capacity of the test piece decreases, and the softening coefficient increases. This indicates that the KDP plays a leading role in improving the water resistance of the MOCFC at this time. The KDP group $\left(\mathrm{PO}^{3-}\right)$ has a strong chelating effect on the $\mathrm{Mg}^{2+}$ metal ions [22], which easily reacts with the $\mathrm{Mg}^{2+}$ in the cement slurry, forming a dense and insoluble complex protective film on the surface of the hydration products, effectively preventing the hydrolysis of the $5 \cdot 1 \cdot 8$ phase, and improving the water resistance of the MOCFC. In view of the trend of the graphics, the addition of the KDP is beneficial in improving its thermal insulation performance, the appropriate addition of KDP, such as adding $1.5 \% \mathrm{KDP}$, will improve the water resistance of the MOCFC.

\section{CONCLUSIONS}

According to the different Ms of the MOCFC and adding the different dosages of the admixtures, the compressive strength, flexural strength, dry apparent density, thermal conductivity, volume water absorption, and softening coefficient of the MOCFC were systematically studied. The following conclusions are drawn based on the analysis of the experimental results:

- The change in the $\mathrm{M}$ changes the pore structure of the MOCFC slurry, which is the main reason for the change of its strength properties, thermal insulation performance and water resistance. Considering the characteristics and environment of the project, M6 was used to study the influence of the different admixtures on the performance of the MOCFC.
- The addition of $\mathrm{H}_{2} \mathrm{O}_{2}$ is beneficial in improving the thermal insulation performance of the MOCFC and preparing thermal insulation materials that are lightweight and have good thermal insulation properties. However, it also restricts the development of the MOCFC mechanical properties and water resistance.

- When FA is added to the MOCFC, the FA mainly acts as a filler, changing the internal structure of the slurry, resulting in a decrease in the water resistance. The addition of the FA helps to improve the thermal insulation performance of the MOCFC, where an excessive FA dosage (such as $15 \%$ FA and $20 \%$ FA) will affect the hydration condensation process, resulting in a decrease in the strength properties of the prepared MOCFC.

- When KDP is added as an admixture to the MOCFC, it primarily plays the role of improving the water resistance of the MOCFC. With an increase in the KDP dosage, the thermal insulation performance of the MOCFC is gradually improved, and its strength performance shows a significant downward trend. The proper addition of KDP (such as $1.5 \%$ ) is beneficial to improve the water resistance of the MOCFC.

\section{Acknowledgements}

This study was supported by the National Natural Science Foundations of China (Grant no. 51662035) and the applied fundamental research project of Qinghai Province (Grant no.2019-ZJ-7005) the Science and Key $R \& D$ and transformation planned project of Qinghai province (Grant no. 2019-NN-159) and the S\&T Foundation Platform of Qinghai Province (Grant no. 2018ZJ-T01) and the teaching team of civil engineering safety technology of Qinghai University (Grant no. TD1804). 


\section{REFERENCES}

1. Yan Y., Jing Y., Ma J. (2008): Advances in magnesium oxychloride cement. Journal of Salt Lake Research, 16(1), 60-66

2. Urwongse L, Sorrell C. A. (1980): The system $\mathrm{MgO}$ $\mathrm{MgCl}_{2}-\mathrm{H}_{2} \mathrm{O}$ at $23{ }^{\circ} \mathrm{C}$. Journal of the American Ceramic Society, 63(9-10), 501-504. doi: 10.1111/j.1151-2916.1980. tb10752.x

3. Li G., Yu, Y., Li J., Wang Y., Liu H. (2003): Experimental study on urban refuse/magnesium oxychloride cement compound floor tile. Cement and Concrete Research, 33(10), 1663-1668. doi: 10.1016/S0008-8846(03)00136-4

4. Li N., Wang Q., Zhang M. (2014): Research on water resistance of magnesium oxychloride cement. Sichuan Cement, 12, 8-11.

5. Zhang C., Deng D. (1995): Research on the water resistance of magnesium oxychloride cement and its improvement. Journal of the Chinese Ceramic Society, 23(6), 673-679.

6. Hu C., Li H., Liu Z., Wang Q. (2016): Research on properties of foamed concrete reinforced with small sized glazed hollow beads. Advances in Materials Science and Engineering, 5820870, 1-8. doi: 10.1155/2016/5820870

7. SayadiA.A, Tapia J.V, Neitzert T. R, and Clifton G.C.(2016): Effects of expanded polystyrene (EPS) particles on fire resistance, thermal conductivity and compressive strength of foamed concrete. Construction and Building Materials, 112, 716-724. doi: 10.1016/j.conbuildmat.2016.02.218

8. Liu M. Y. J, Alengaram U. J, Jumaat M. Z, Mo K. H. (2014): Evaluation of thermal conductivity, mechanical and transport properties of lightweight aggregate foamed geopolymer concrete. Energy and Buildings, 72, 238-245. doi: 10.1016/j.enbuild.2013.12.029

9. Zuhui Z, Provis J. L, Reid A, Hao W. (2015): Mechanical, thermal insulation, thermal resistance and acoustic absorption properties of geopolymer foam concrete. Cement and Concrete Composites, 62, 97-105. doi: 10.1016/j.cemconcomp.2015.03.013

10. Wei S, Yiqiang C, Yunsheng Z, Jones M. R. (2013): Characterization and simulation of microstructure and thermal properties of foamed concrete. Construction and Building Materials, 47(10), 1278-1291.8. doi: 10.1016/j. conbuildmat.2013.06.027

11. Jiang J., Lu Z., Niu Y., Li J., Zhang, Y. (2016): Study on the preparation and properties of high-porosity foamed concretes based on ordinary Portland cement. Materials and Design, 92, 949-959. doi: 10.1016/j.matdes.2015.12.068

12. Wee T. H, Daneti S. B, and Tamilselvan T. (2011): Effect of $\mathrm{w} / \mathrm{c}$ ratio on air-void system of foamed concrete and their influence on mechanical properties. Magazine of Concrete Research, 63(8), 583-595. doi: 10.1680/macr.2011.63.8.583

13. Yang K, Lee K. (2013): Tests on alkali-activated slag foamed concrete with various water-binder ratios and substitution levels of fly ash. Journal of Building Construction and Planning Research, 1(1), 8-14. doi: 10.4236/jbcpr. 2013.11002

14. British Cement Association (1994). Foamed Concrete. In: Composition and Properties, pp. 4.

15. Dai M., Zhang H. (2013): Optimization test of magnesium oxychloride cement foam concrete. Concrete, 3(38), 1002-3550.
16. Lange F., Mörtel H., Rudert V. (1997): Dense packing of cement pastes and resulting consequences on mortar properties. Cement and Concrete Research, 27(10), 1481-1488. doi: 10.1016/S0008-8846(97)00189-0

17. Olorunsogo F. T. (1998): Particle size distribution of GGBS and bleeding characteristics of slag cement mortars. Cement and Concrete Research, 28(6), 907-919. doi: 10.1016/ S0008-8846(98)00042-8

18. Foreign Langue Institute of Tsinghua University (1999). An English-Chinese dictionary of science and technology. Beijing: Nation Defense Press.

19. Nehdi M., Mindess S., Aïtcin P. C. (1998): Rheology of high-performance concrete: effect of ultrafine particles. Cement and Concrete Research, 28(5), 687-697. doi: 10.1016/S0008-8846(98)00022-2

20. Kearsley E. P., Wainwright P. J. (2001): Porosity and permeability of foamed concrete. Cement and Concrete Research, 31, 805-812. doi: 10.1016/S0008-8846(01) 00490-2

21. Wainwright P. J., Kearsley E. P. (2002): The effect of porosity on the strength of foamed concrete. Cement and Concrete Research, 32, 233-239. doi: 10.1016/S0008-8846 (01)00665-2

22. Chen N. (2005). Synthesis of functional phosphate ester and application in coating. Master's Thesis, Guangdong University of Technology.

23. Dong J. M, Yu H. F, Zhang L. M. (2010): Study on experimental conditions of hydration methods of determining active magnesium oxide content, Journal of Salt Lake Research, 18(1), 38-41.

24. Zhenguo L, Zesheng J (2015): Effect of Molar Ratios on Compressive Strength of Modified Magnesium Oxysulfate Cement. International Journal of Hybrid Information Technology, 8(6), 87-94. doi:10.14257/ijhit.2015.8.6.09.

25. Jones M.R., McCarthy A. (2006): Heat of hydration in foamed concrete: Effect of mix constituents and plastic density Cement and Concrete Research, 36(6), 1032-1041. doi: 10.1016/j.cemconres.2006.01.011

26. Kearsley E., Wainwright P.J. (2001): Porosity and permeability of foamed concrete. Cement and Concrete Research, 3(1), 805-812. doi: 10.1016/S0008-8846(01)00490-2

27. Nambiar E. K., Ramamurthy K. (2009): Shrinkage behavior of foam concrete. Journal of Materials in Civil Engineering, 21(11), 631-636. doi: 10.1061/(ASCE)0899-1561 (2009)21:11(631)

28. Jun L., Wei Q., Ruiqing L., Yue T. (2016): Study on the relationship between compressive strength and pore characteristics of hydrogen peroxide foamed foam concrete. Concrete, 5, 1-4.

29. Wei H., Xingwen J. (2015): Application of Catalysts in Hydrogen Peroxide Foamed Ultralight Foam Concrete. Building Blocks and Block Buildings. 41-44.

30. Chindaprasirt P., Jaturapitakkul C., Sinsiri, T. (2007): Effect of fly ash fineness on microstructure of blended cement paste. Construction and Building Materials, 21(7), 1534-1541. doi: 10.1016/j.conbuildmat.2005.12.024

31. Narayanan N., Ramamurthy K. (2000): Microstructural investigations on aerated concrete. Cement and Concrete Research, 30, 457-464. doi: 10.1016/S0008-8846(00) 00199-X 